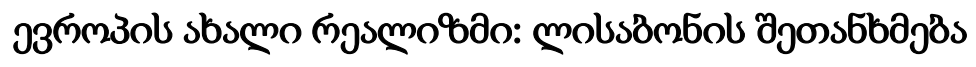

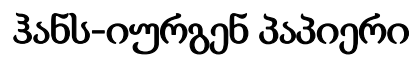

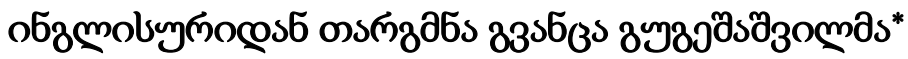

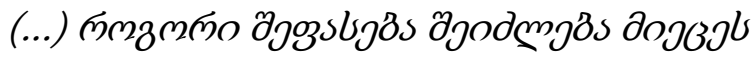

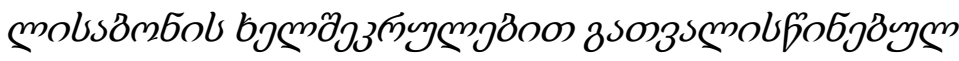

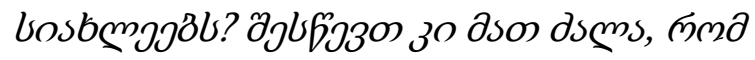

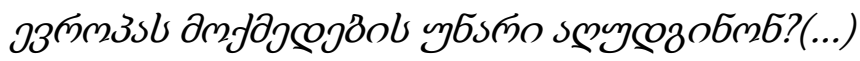

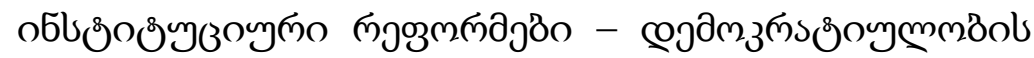

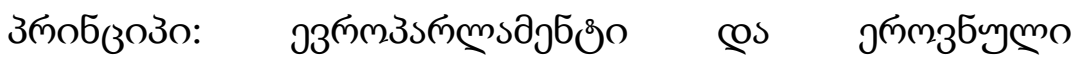

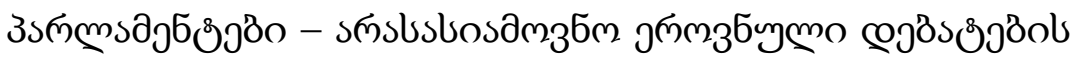

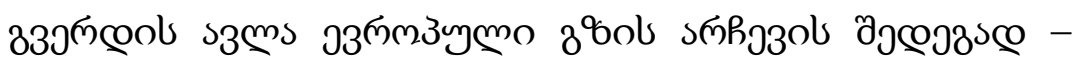

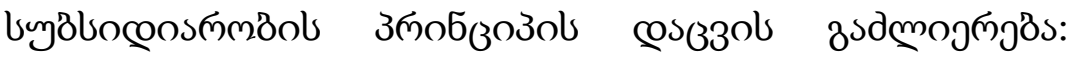

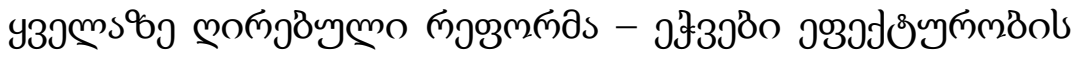

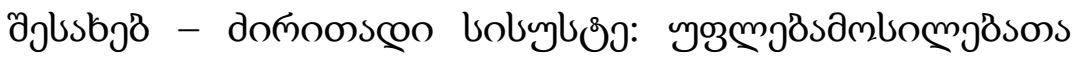

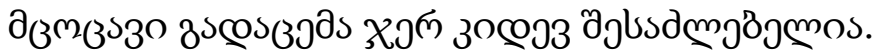

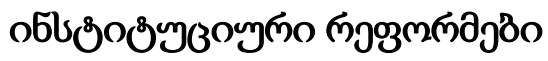

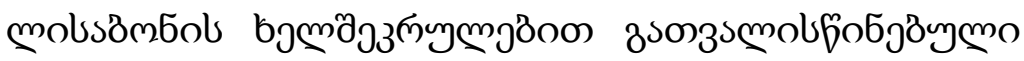

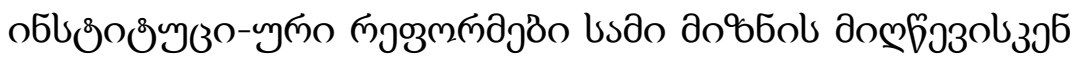

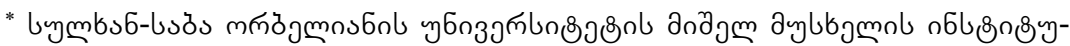

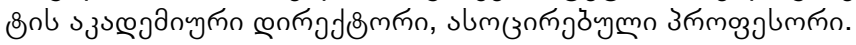
orcid.org/0000-0003-4586-2731
} 


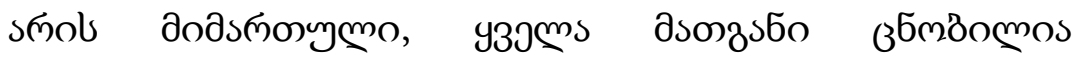

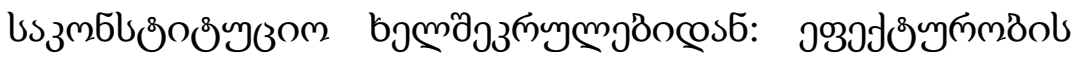

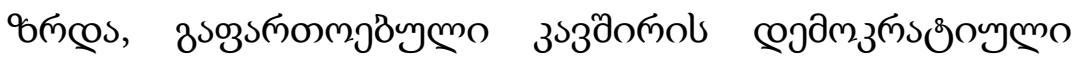

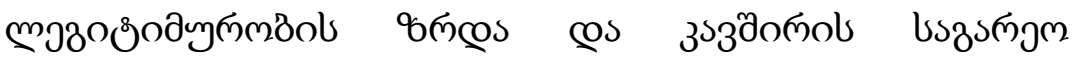

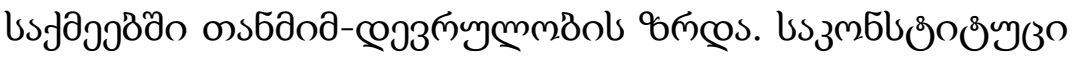

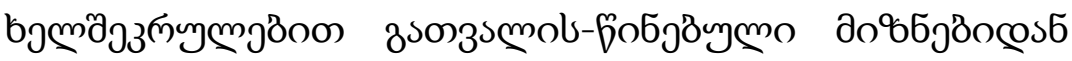

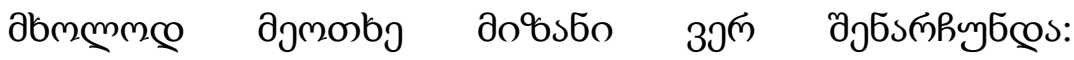

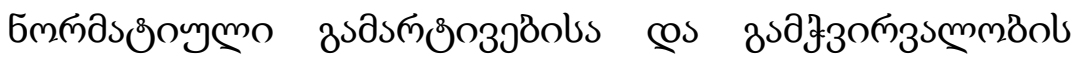

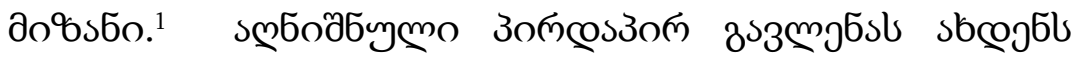

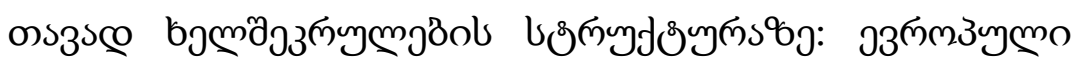

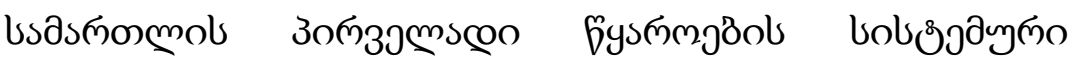

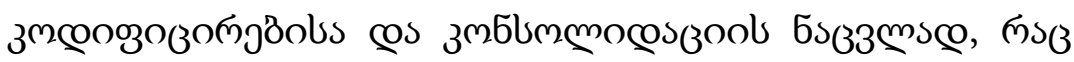

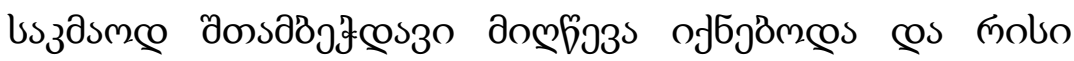

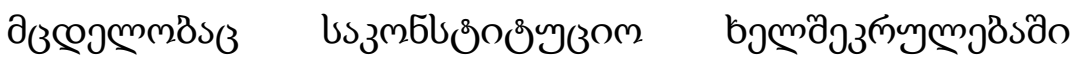

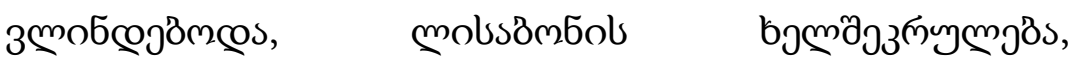

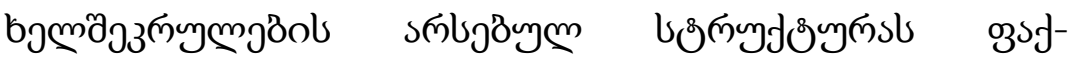

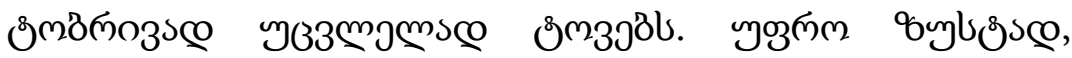

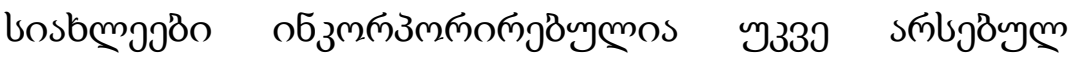

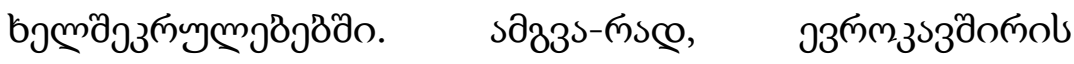

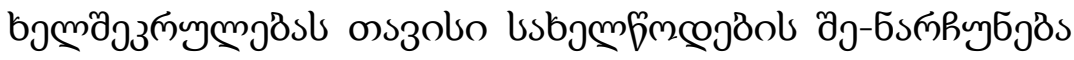

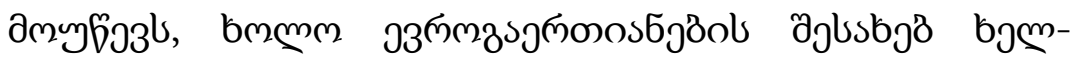

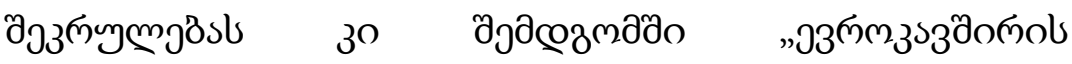

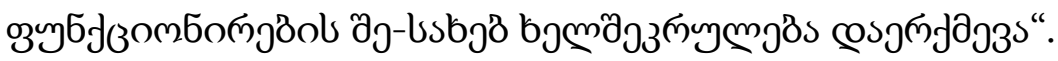

\footnotetext{
1 ob., Peter-Christian Muller-Graff, 'Die Zukunft des europaischen Verfassungstopos und Primarrechts nach der deutschen Ratsprasidentschaft', speech at Forum Constitutionis Europae, 27 June 2007, FCE 6/07, <http://whi-berlin.de/fce/2007.dhtml>, (33. 20).
} 


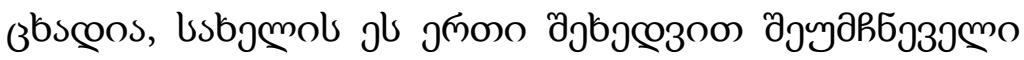

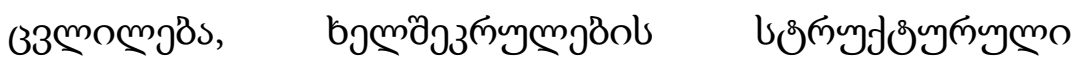

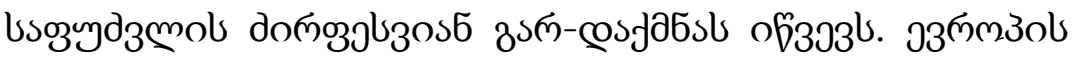

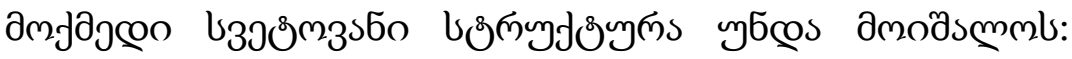

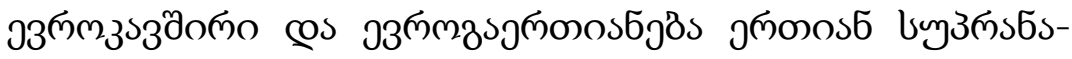

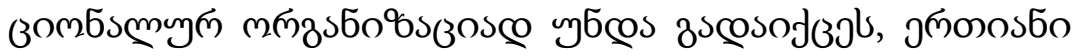

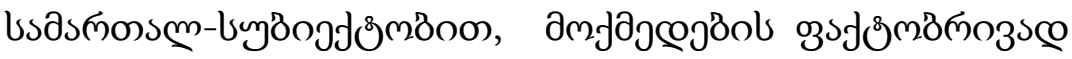

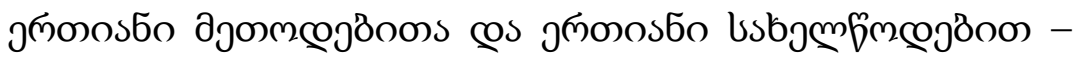

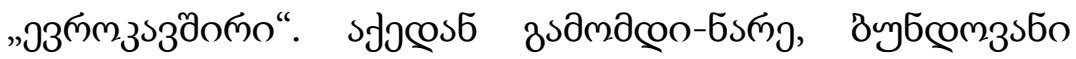

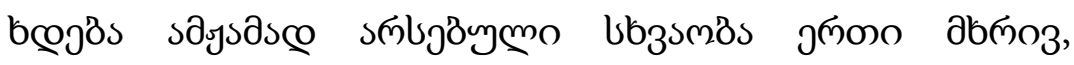

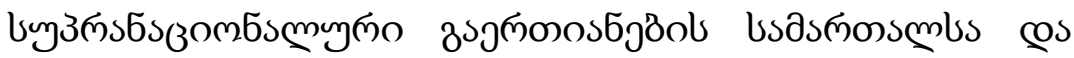

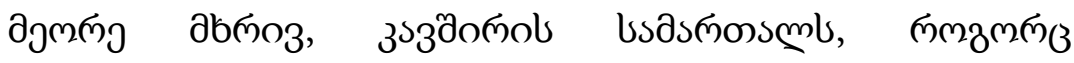

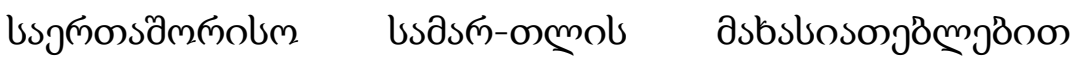

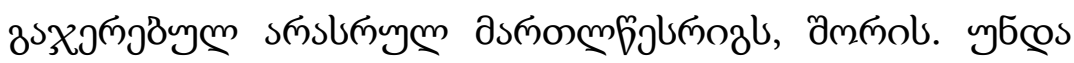

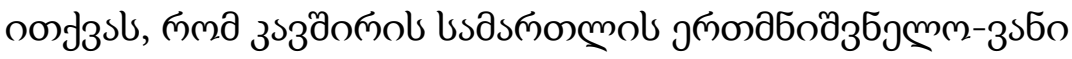

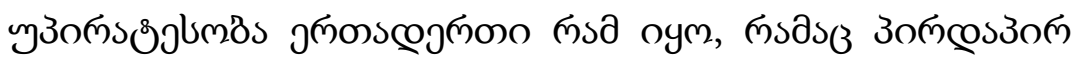

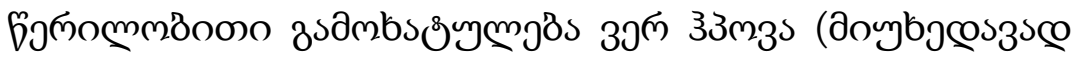

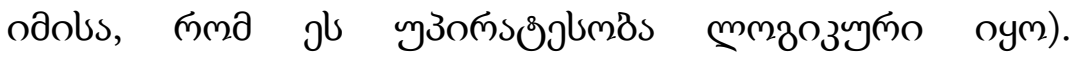

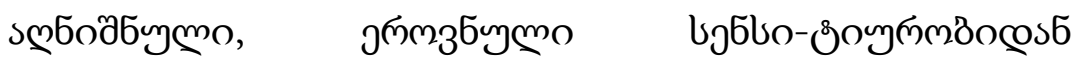

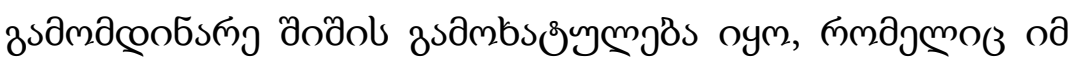

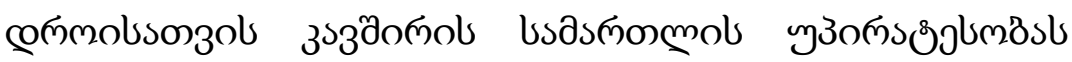

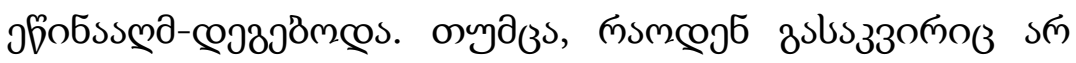

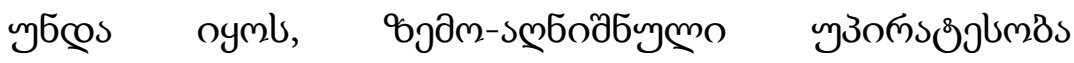

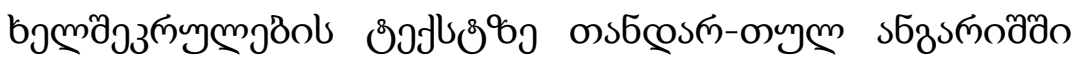
coscosbsimnূos. 
доммоรБm8sð̊o,

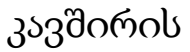
мпुзsбo:s

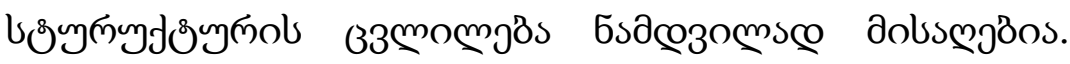

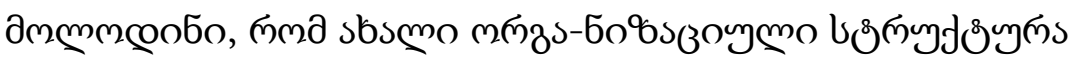

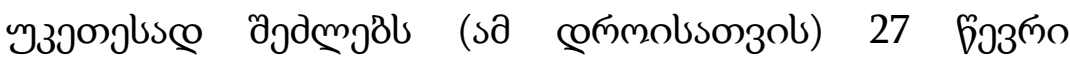

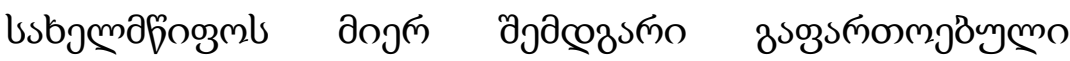

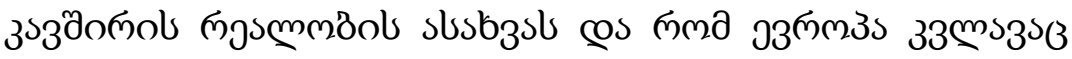

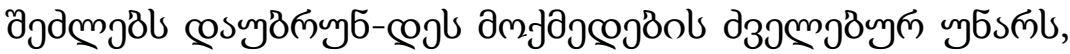

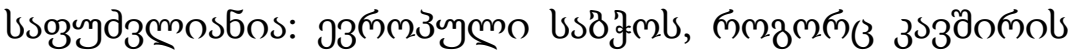

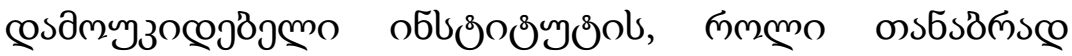

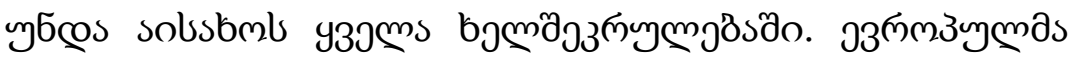

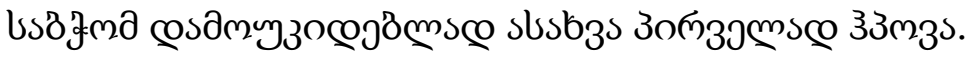

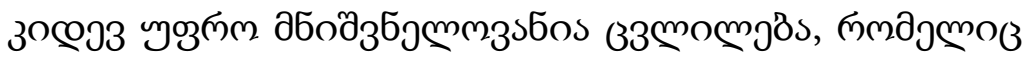

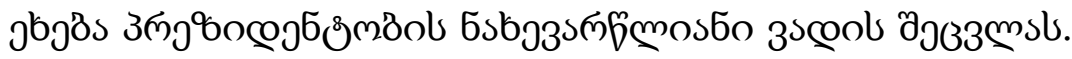

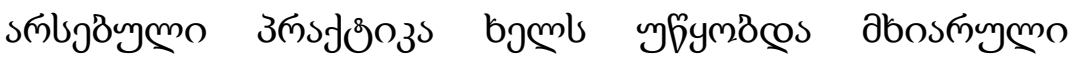

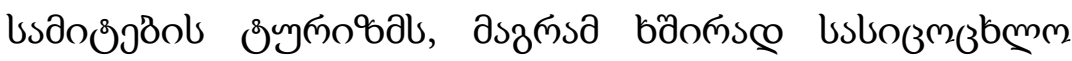

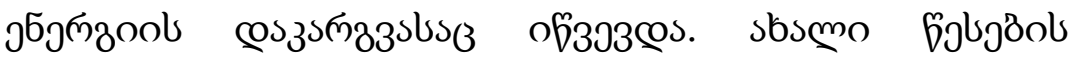

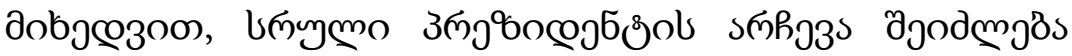

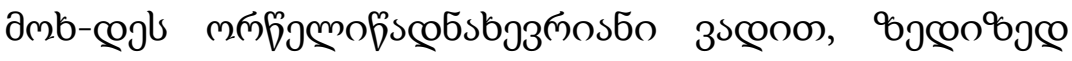

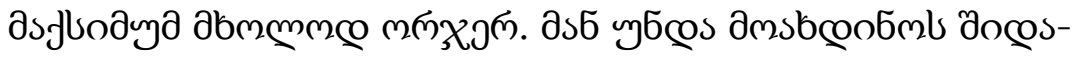

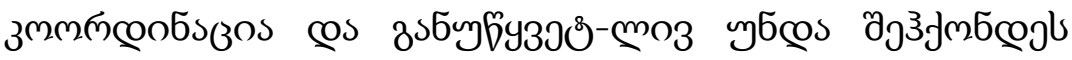

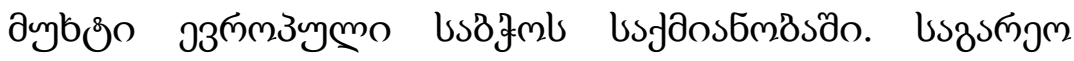

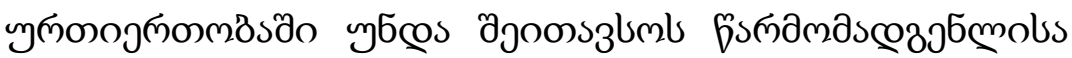

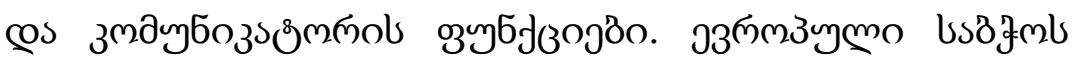

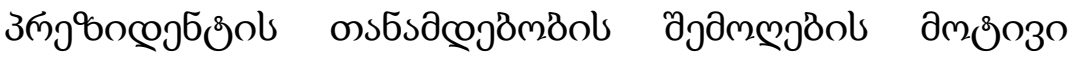

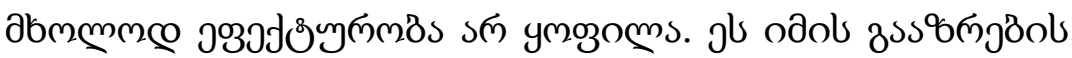

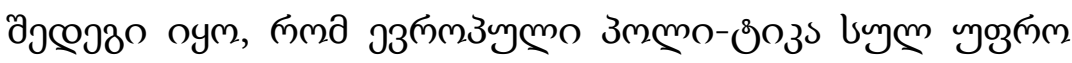




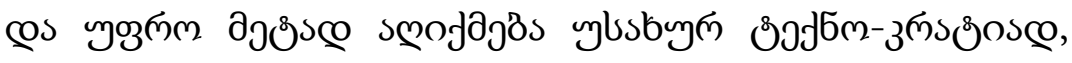

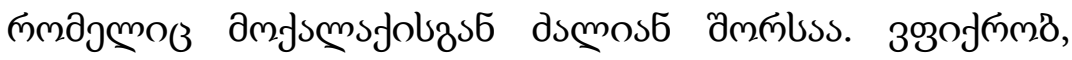

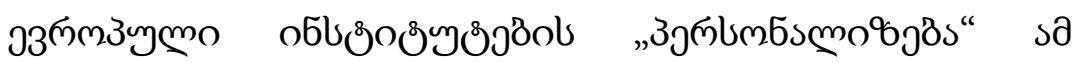

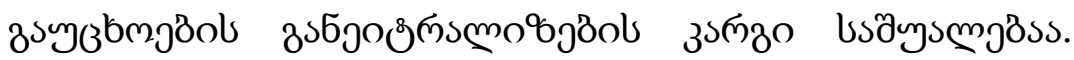

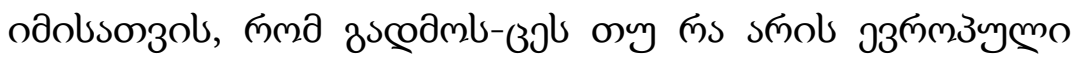

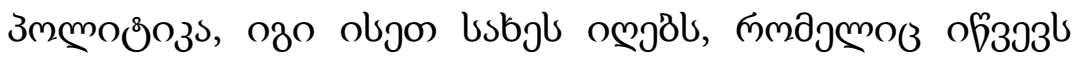

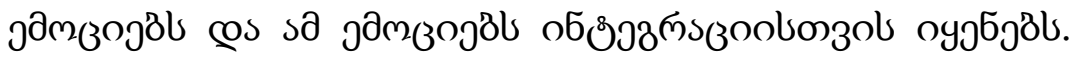

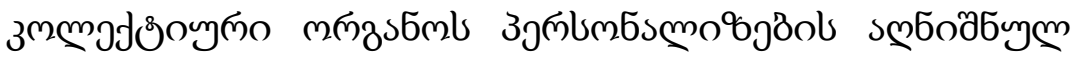

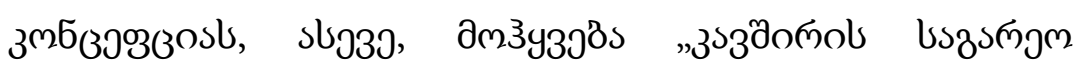

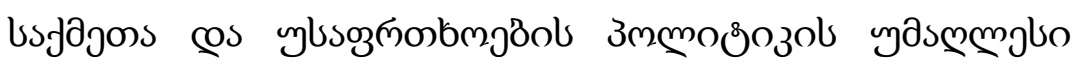

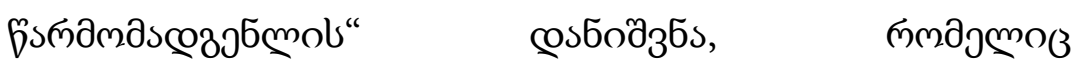

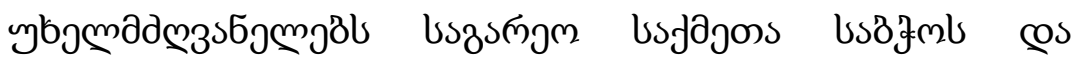

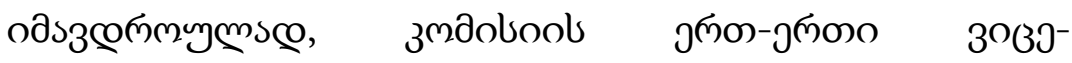

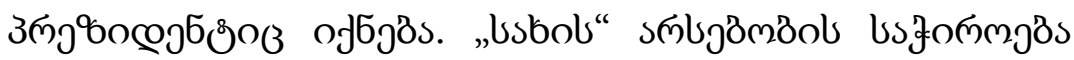

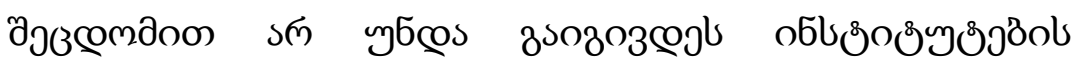

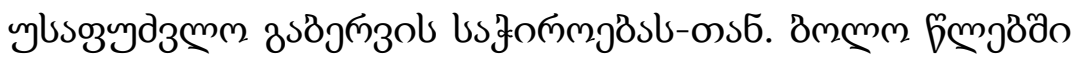

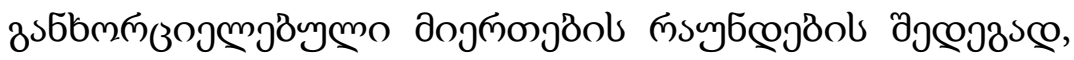

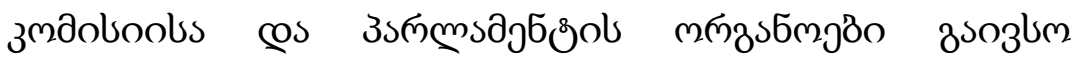

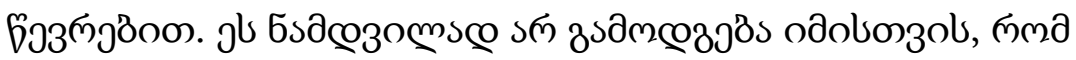

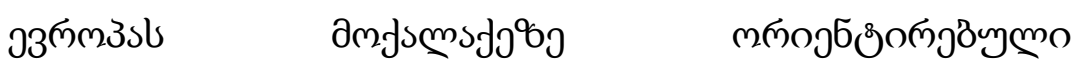

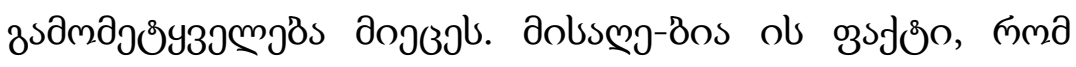

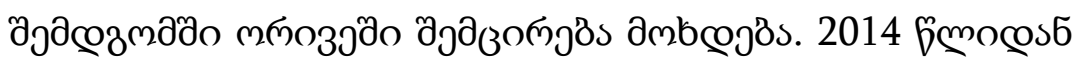

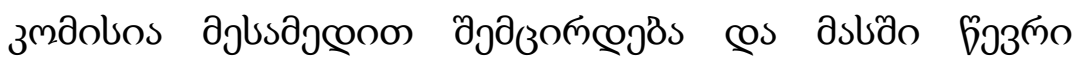

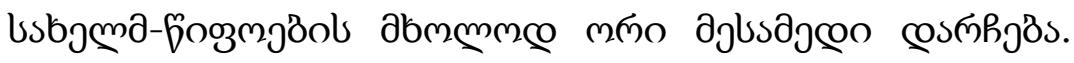

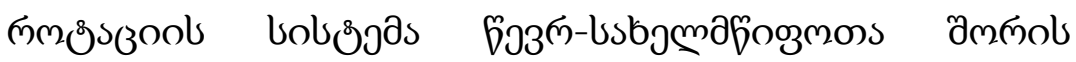

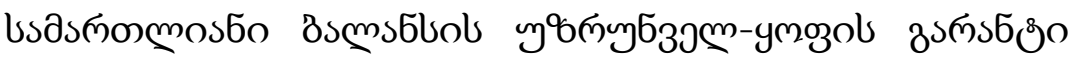




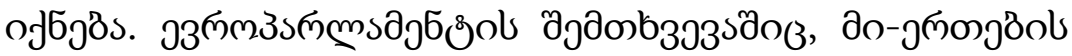

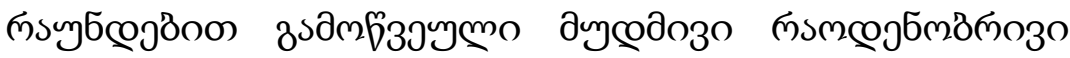

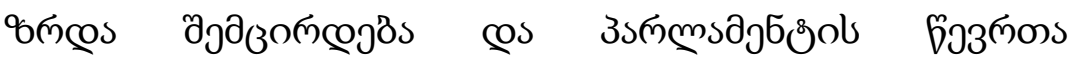

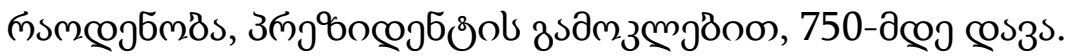

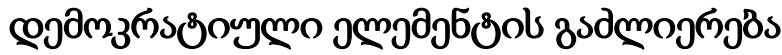

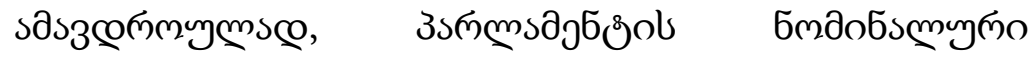

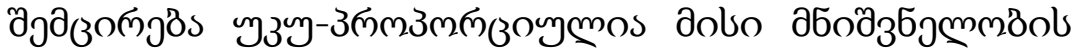

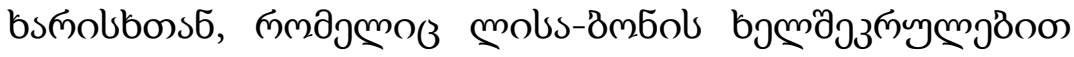

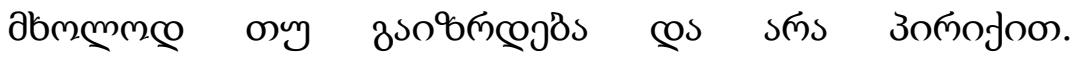

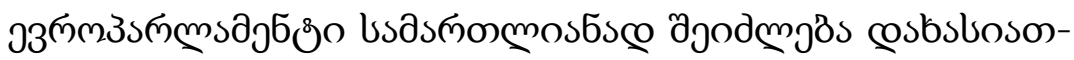

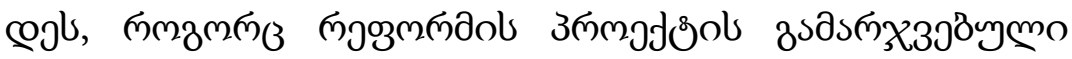

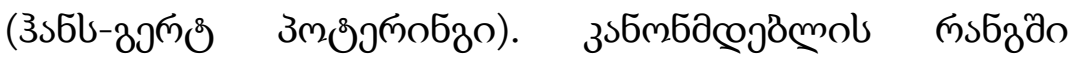

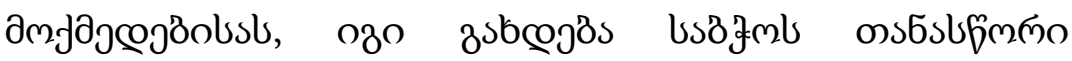

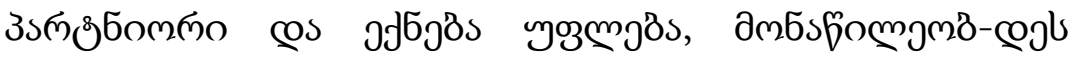

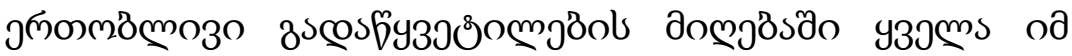

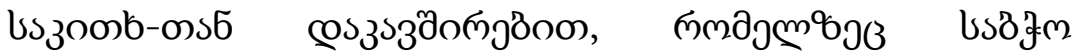

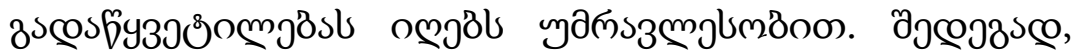

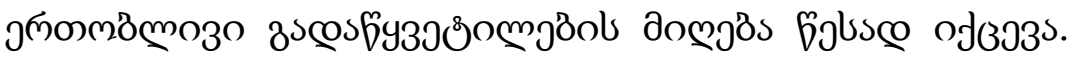

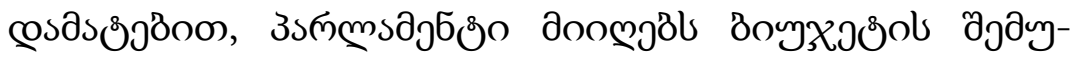

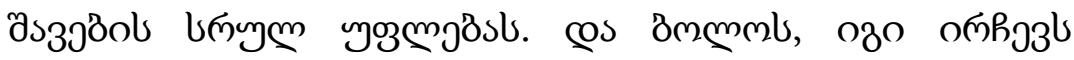

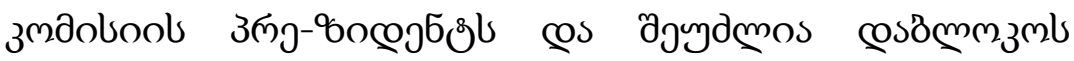

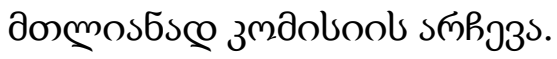

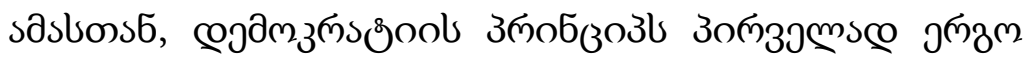

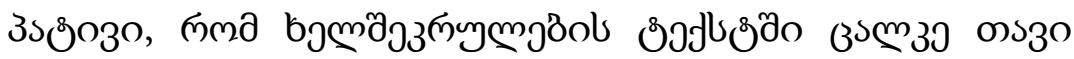




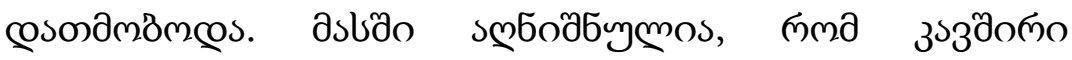

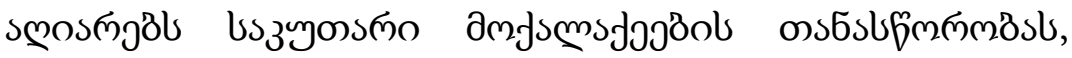

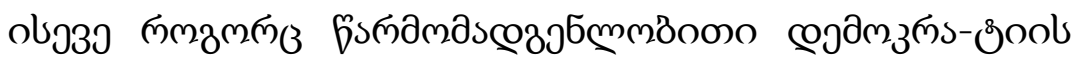

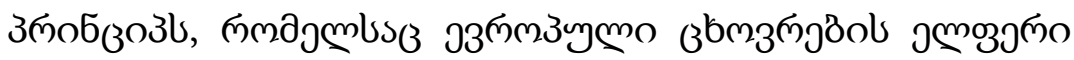

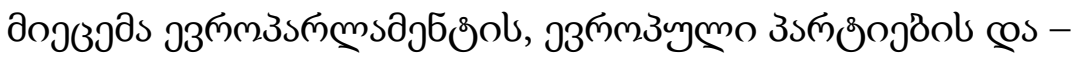

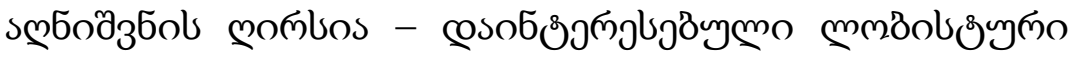

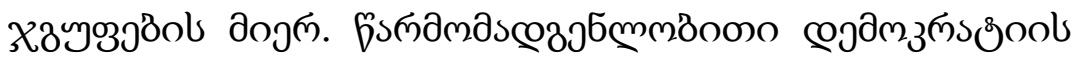

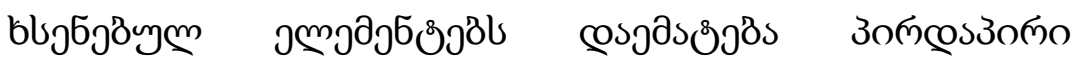

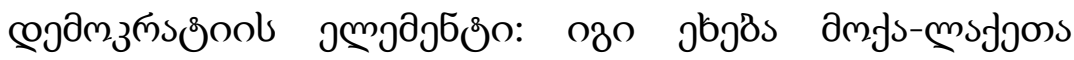

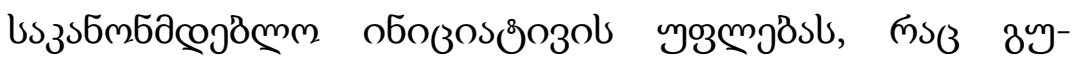

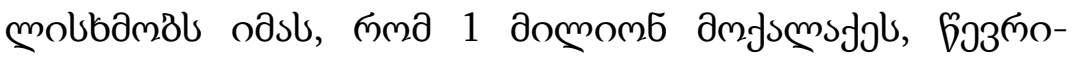

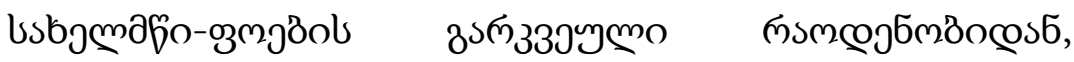

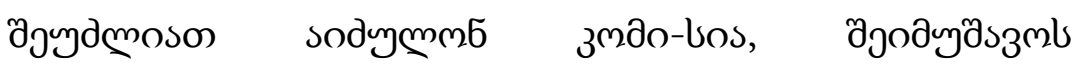

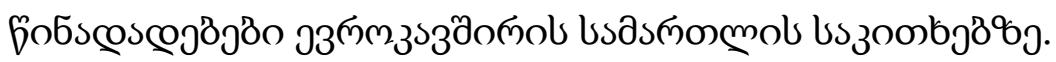

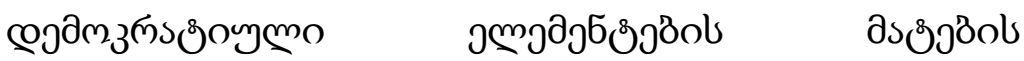

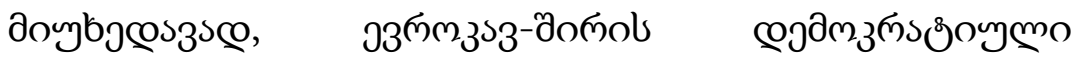

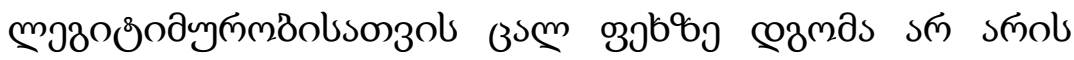

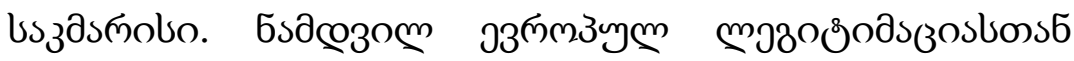

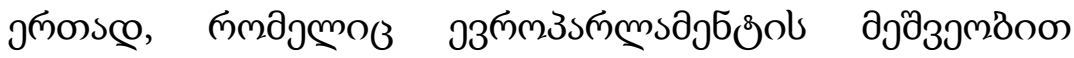

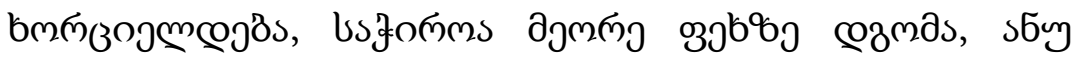

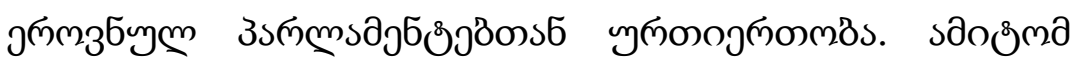

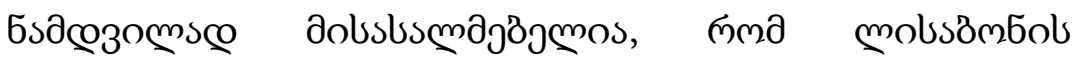

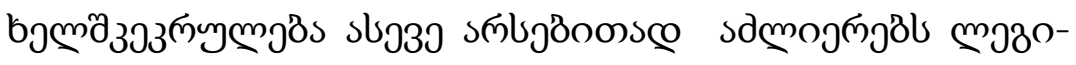

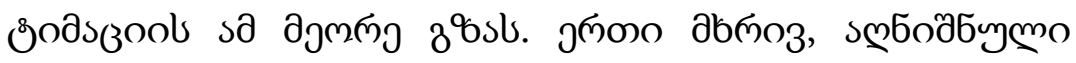

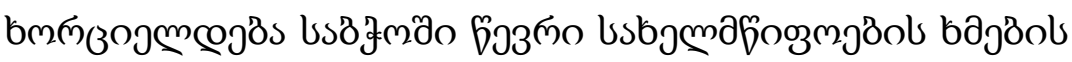

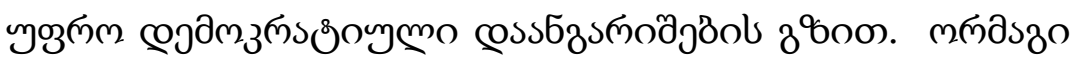




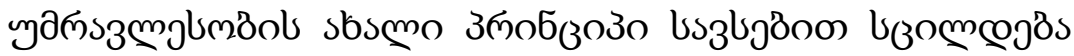

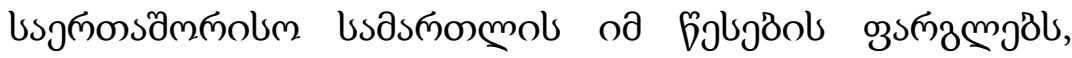

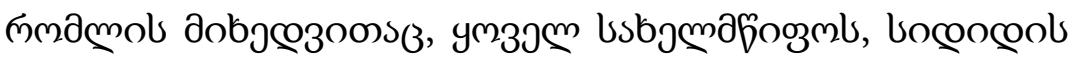

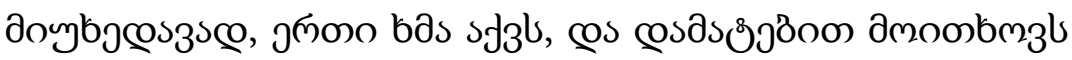

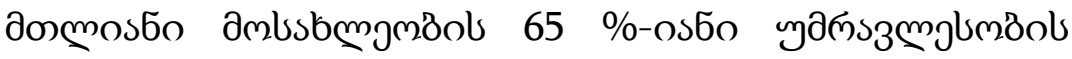

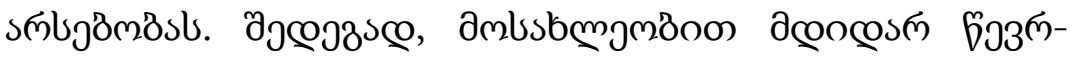

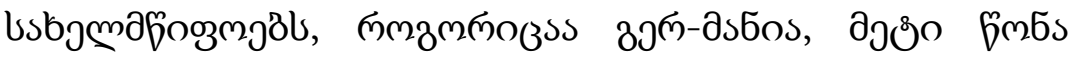

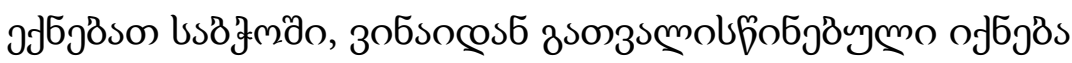

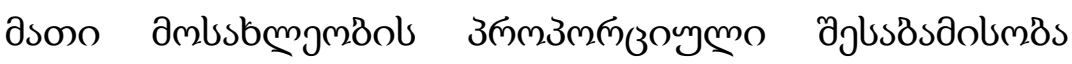

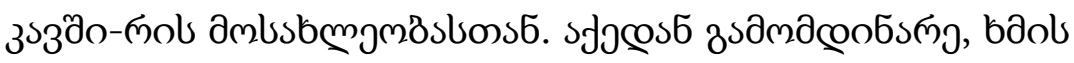

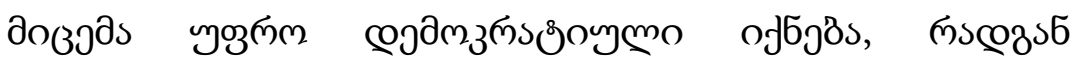

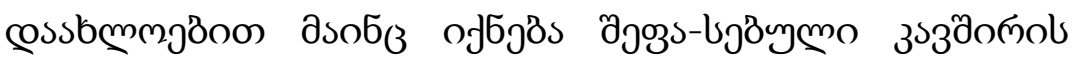

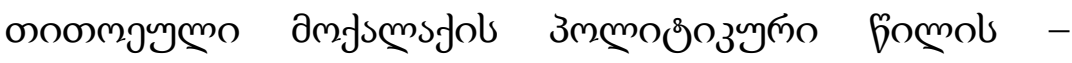

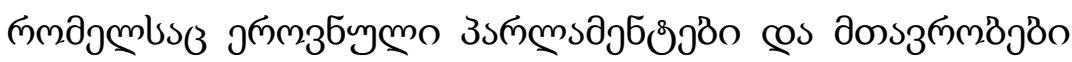

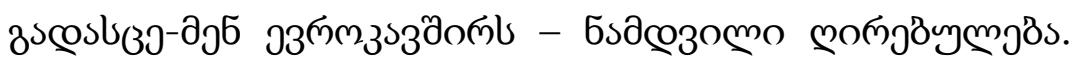

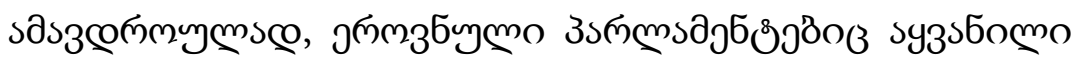

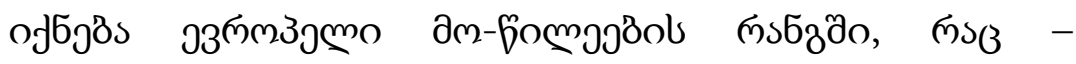

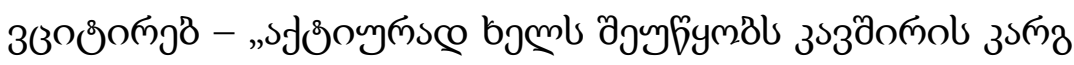

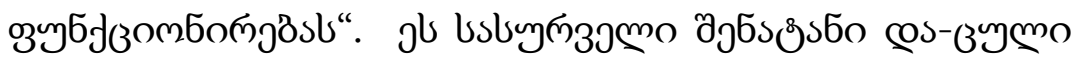

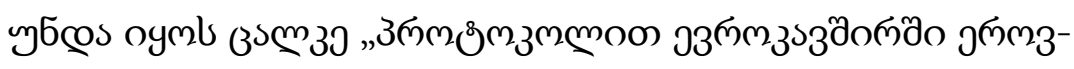

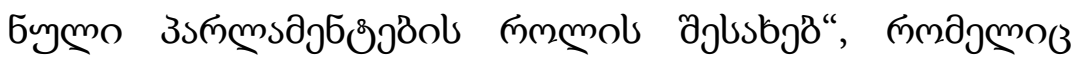

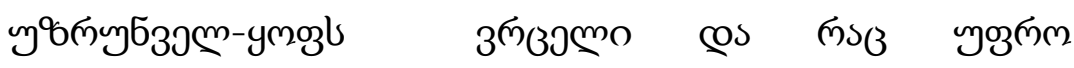

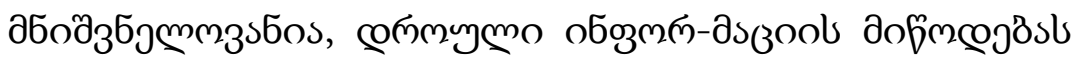

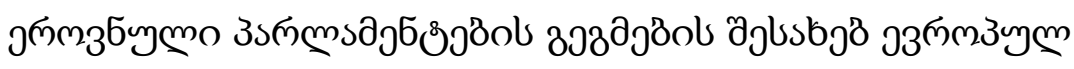

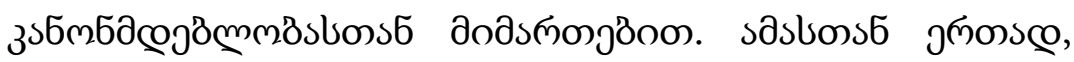

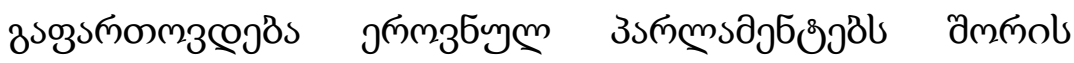




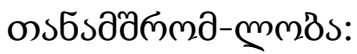

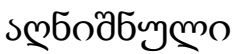

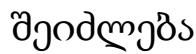

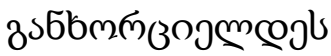

us3s๘ms

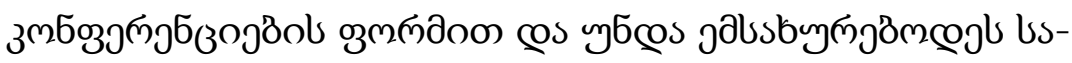

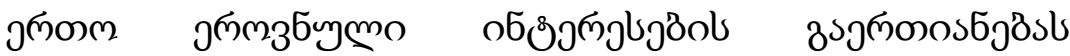

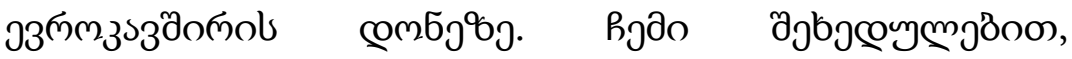

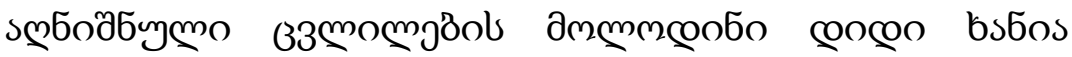

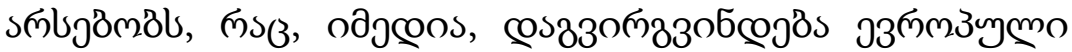

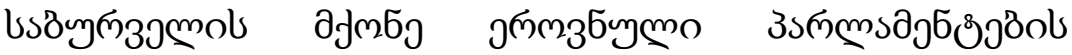

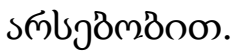

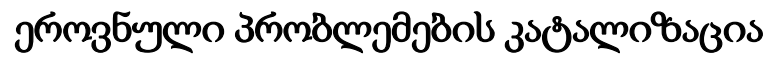

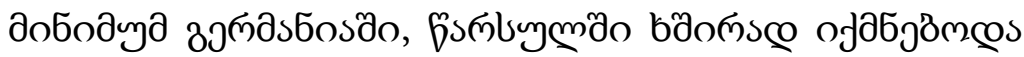

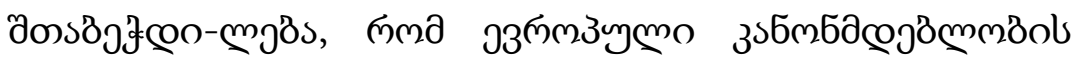

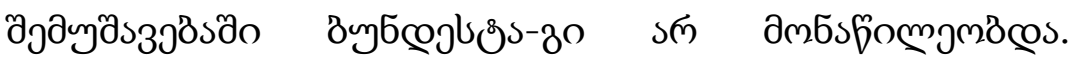

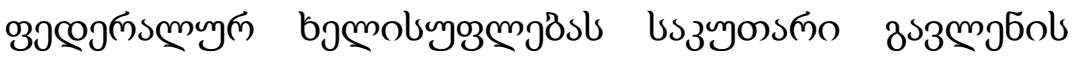

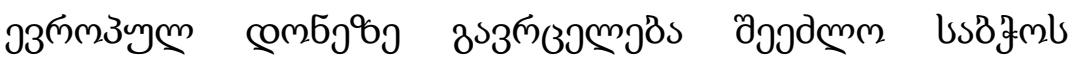

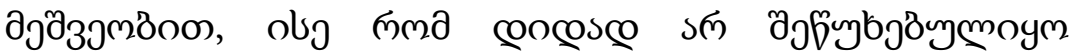

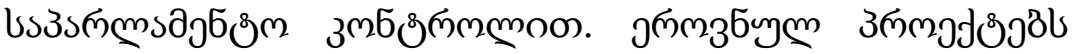

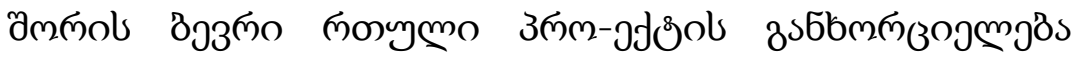

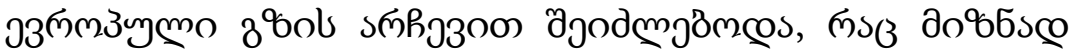

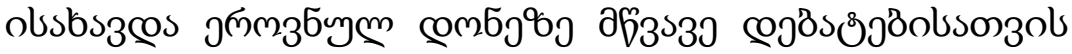

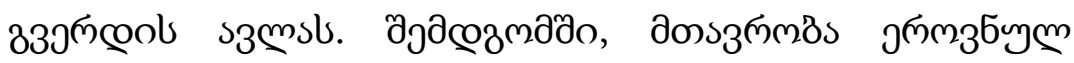

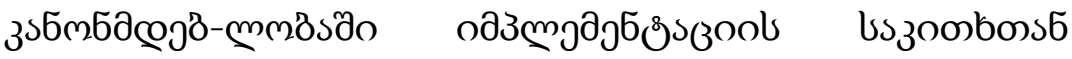

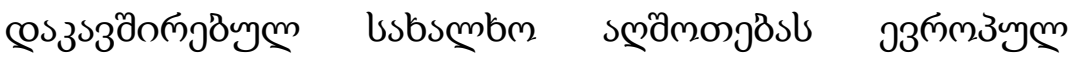

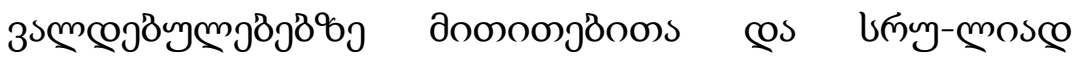




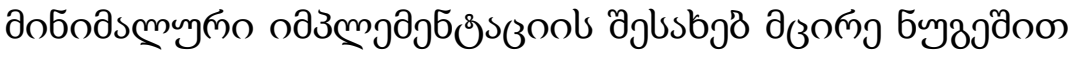

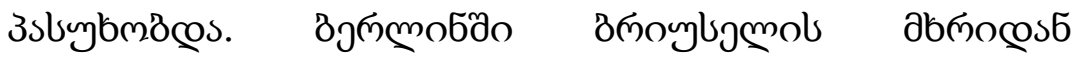

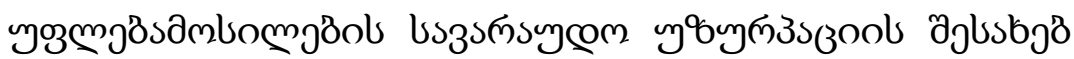

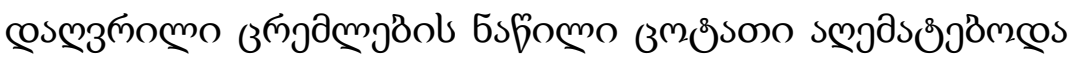

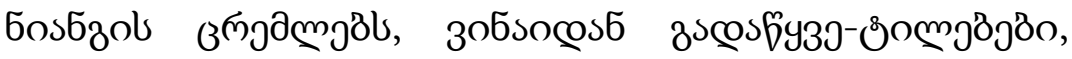

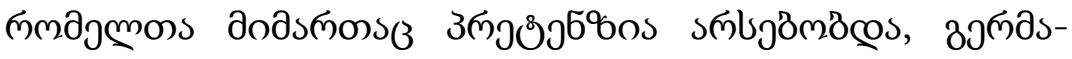

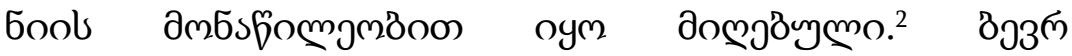

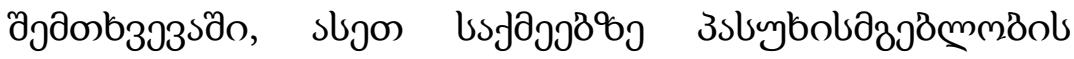

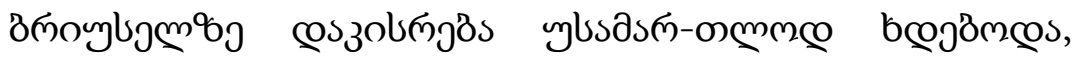

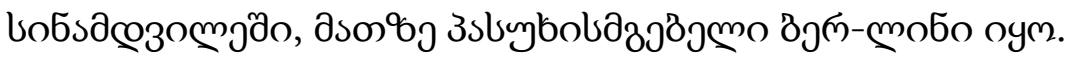

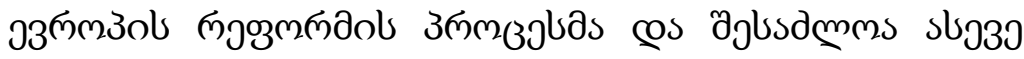

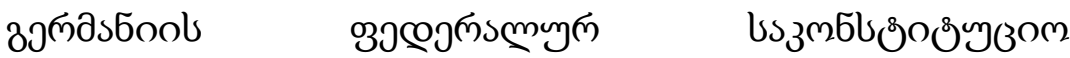

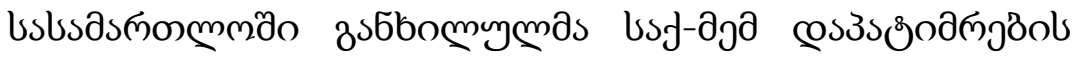

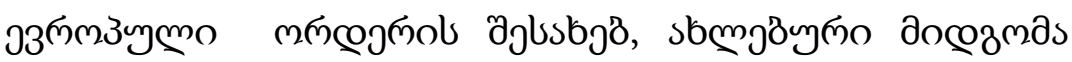

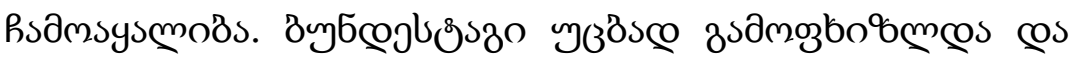

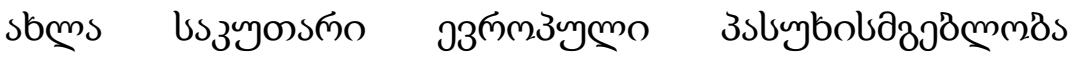

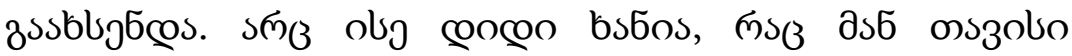

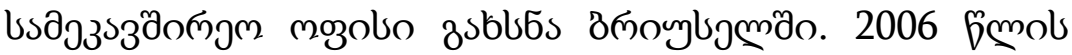

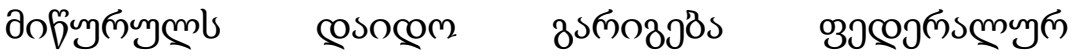

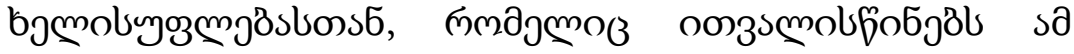

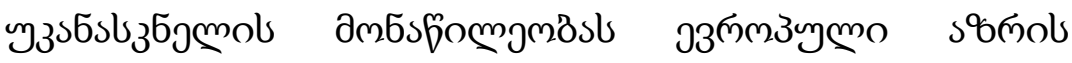

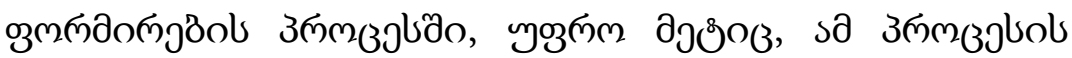

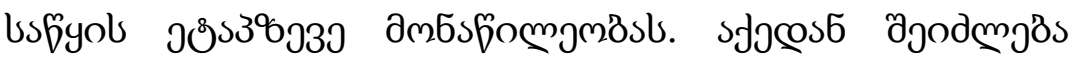

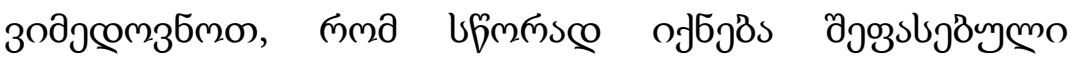

2 nb. Ralph Alexander Lorz, 'Kompetenzverteilung im europischen Mehrebenensystem', EuR - Supplement 1-2006, p. 43 (44). 


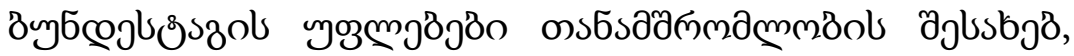

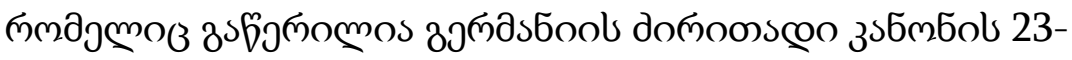

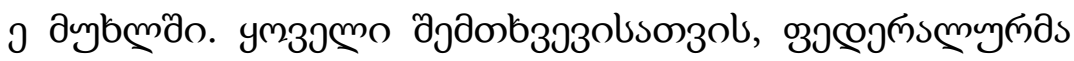

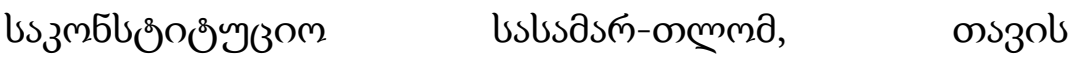

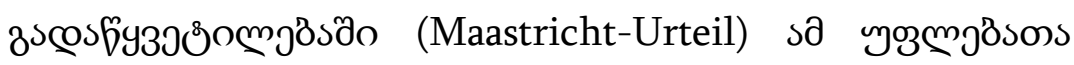

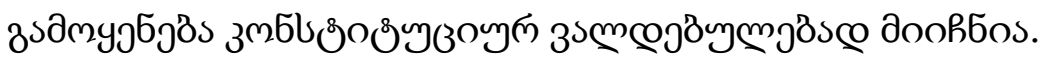

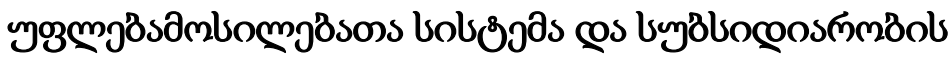 зщобъозо}

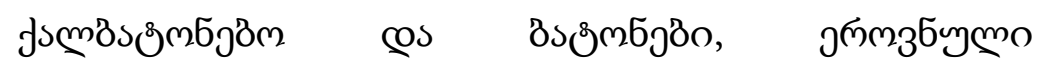

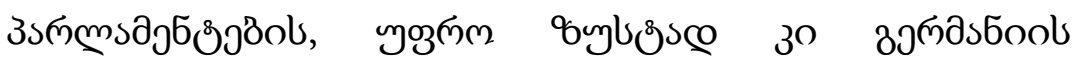

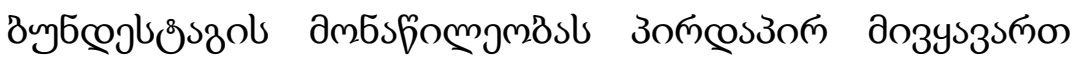

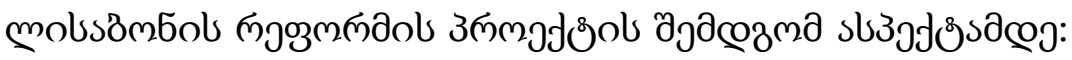

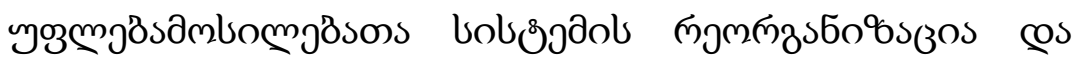

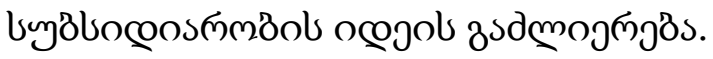

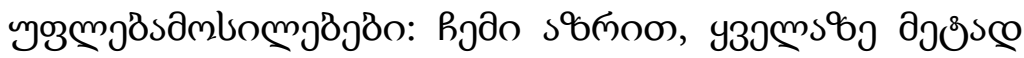

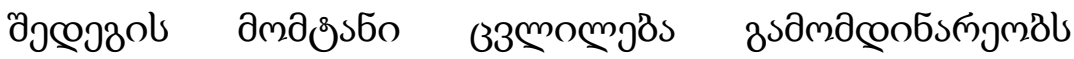

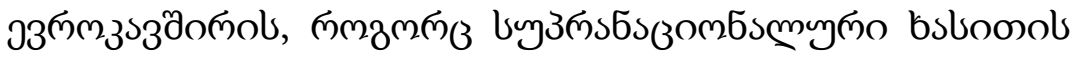

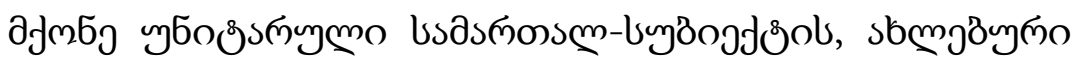

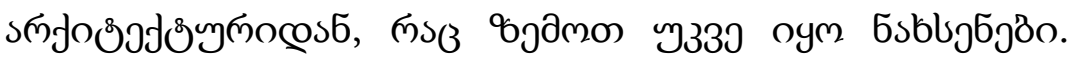

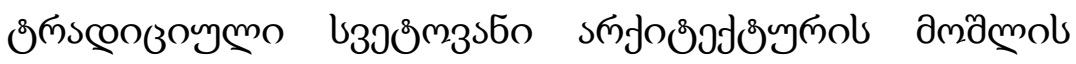

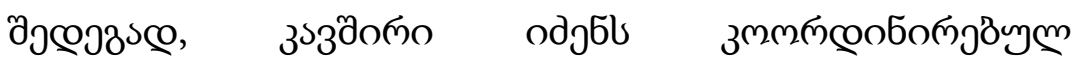

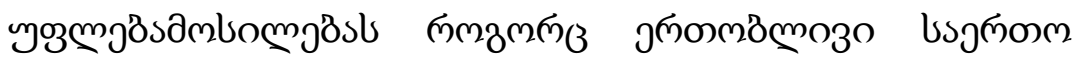

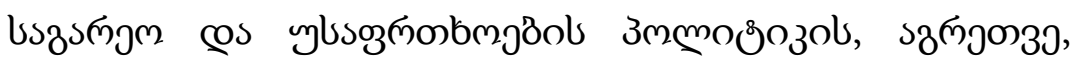

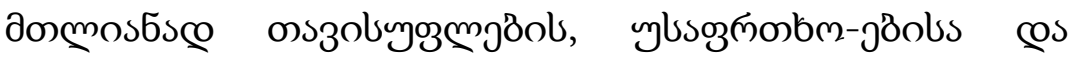




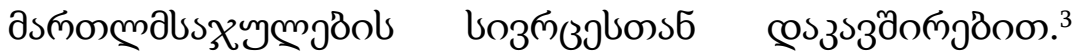

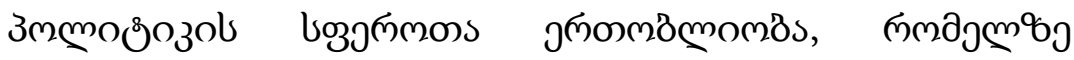

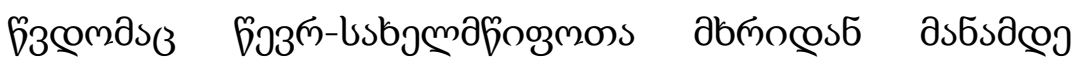

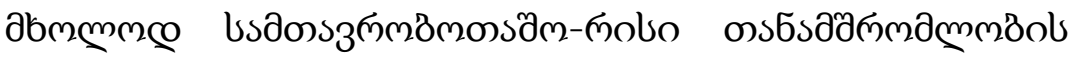

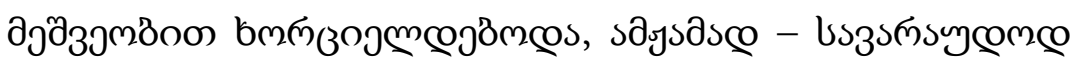

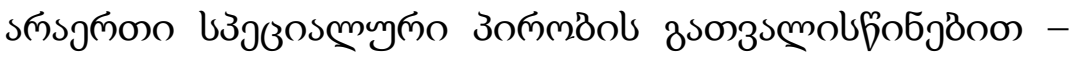

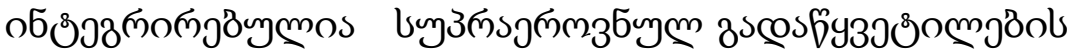

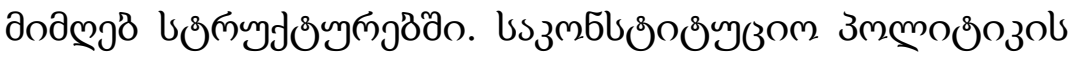

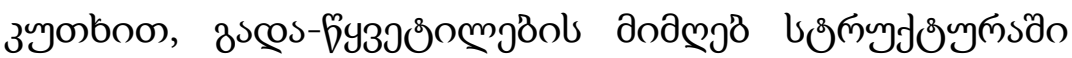

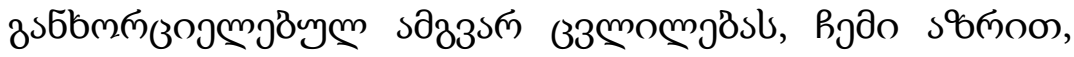

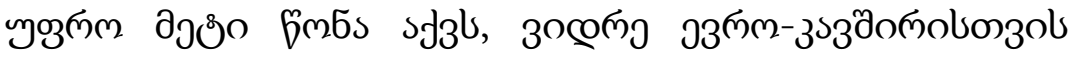

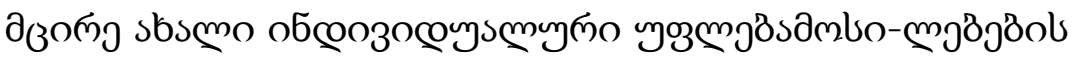

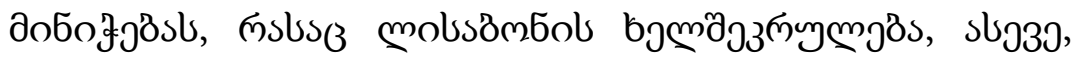

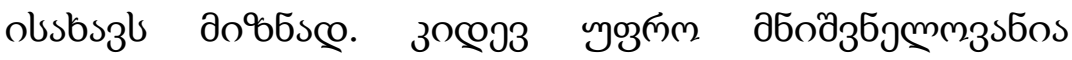

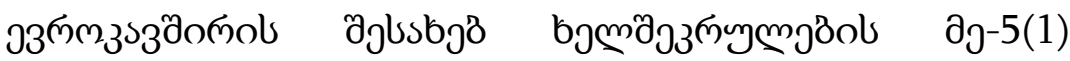

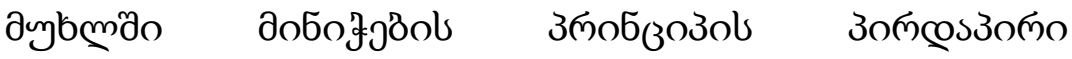

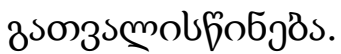

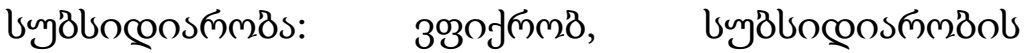

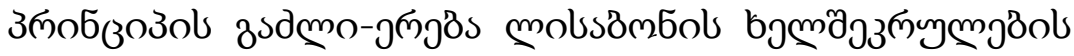

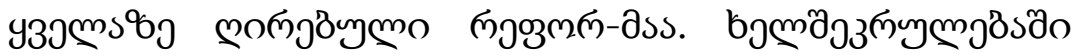

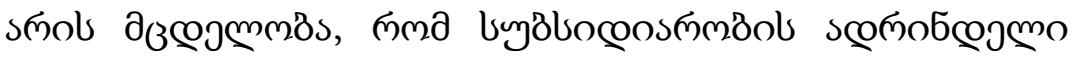

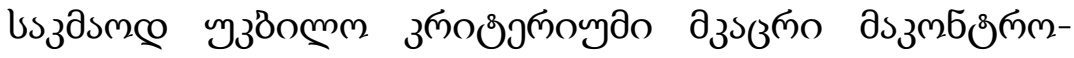

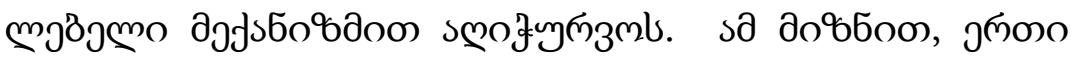

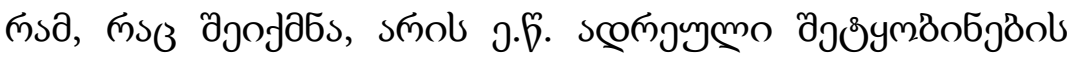

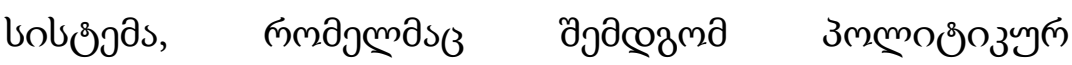

${ }^{3}$ Supra n.1 (p.7) 


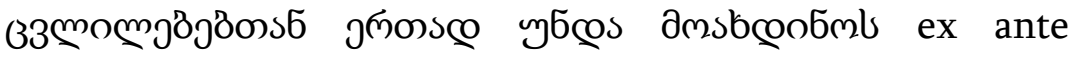

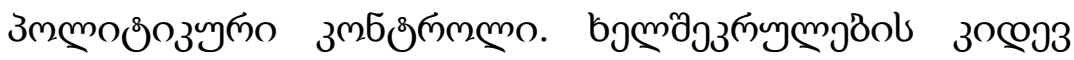

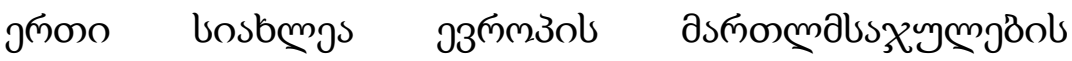

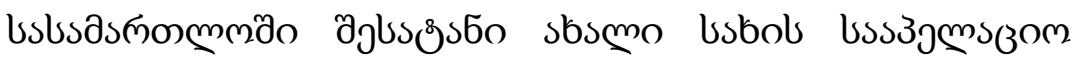

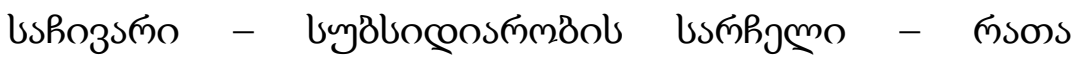

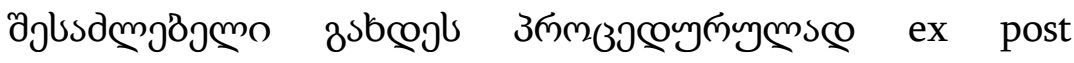

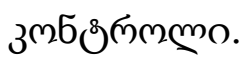

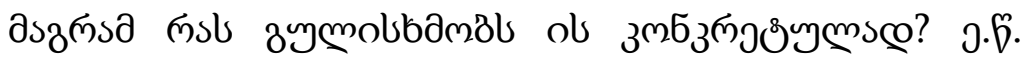

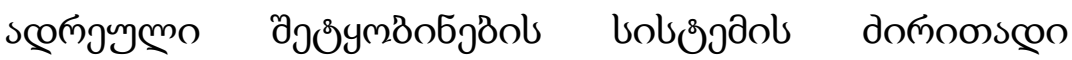

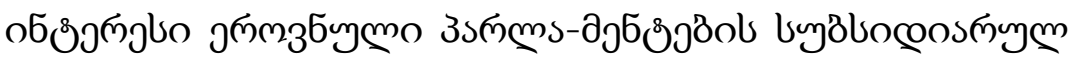

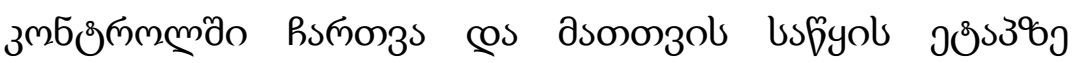

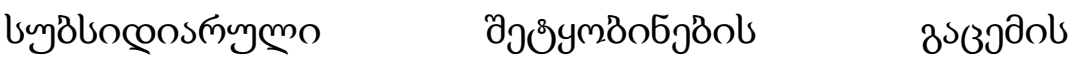

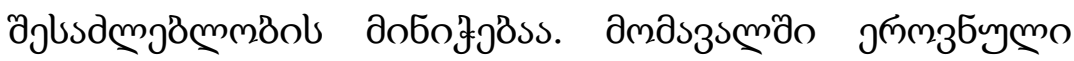

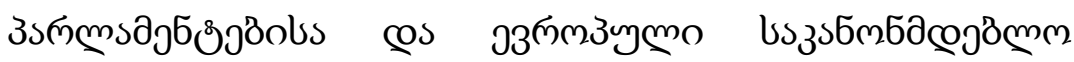

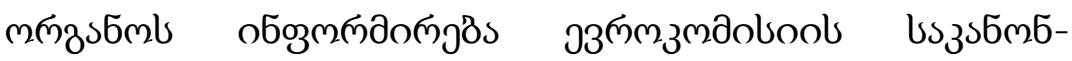

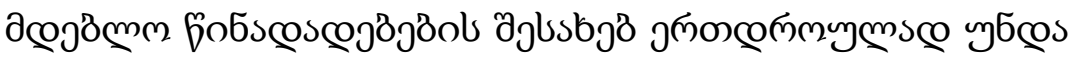

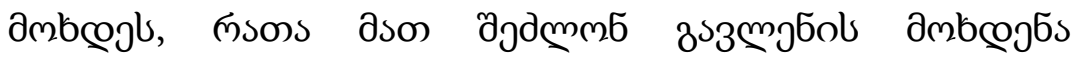

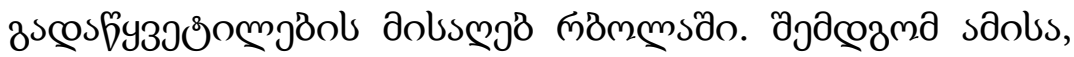

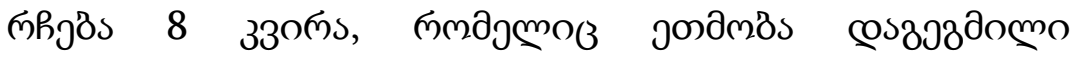

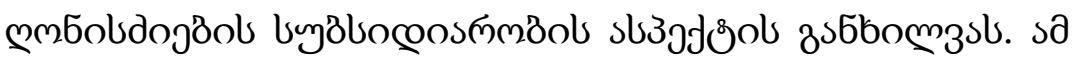

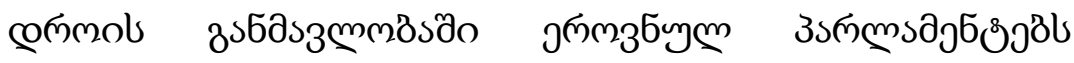

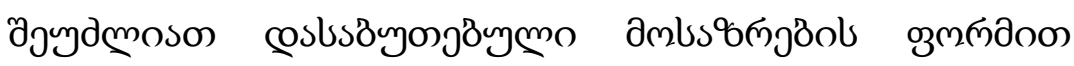

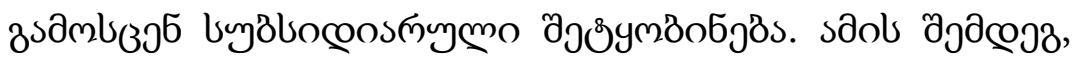

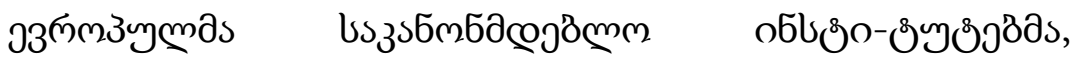

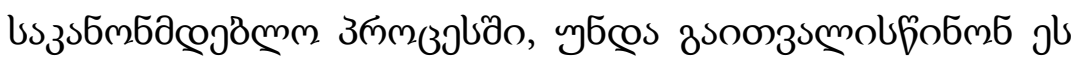

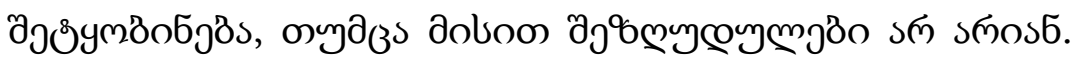




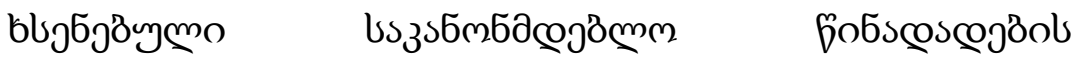

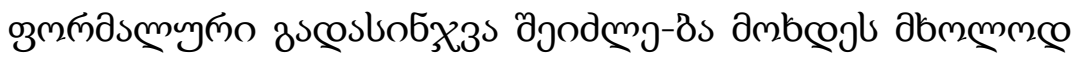

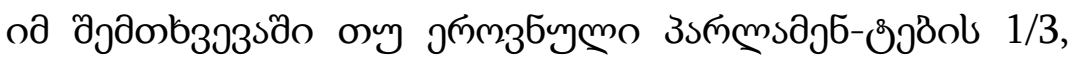

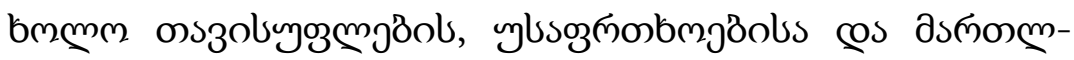
alszxymgiol bo3m

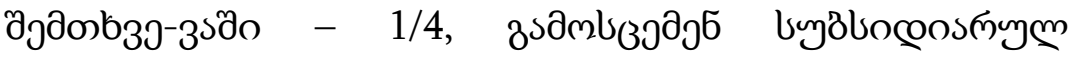

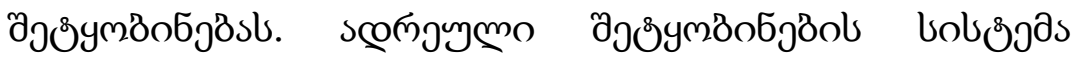

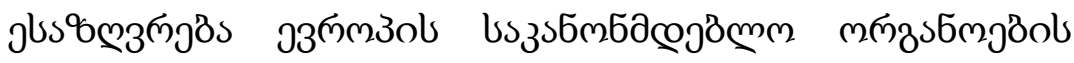

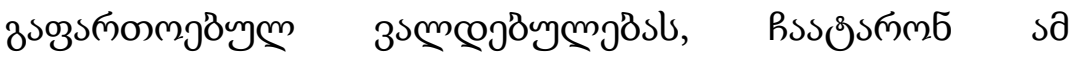

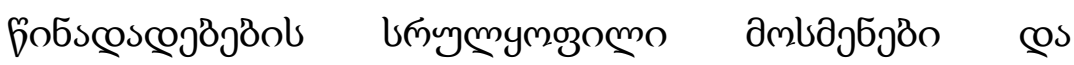

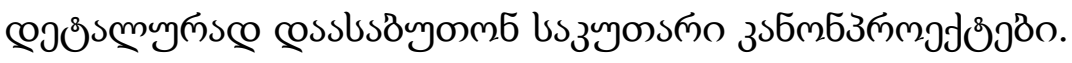

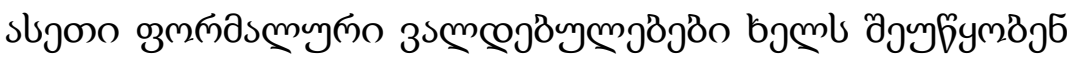

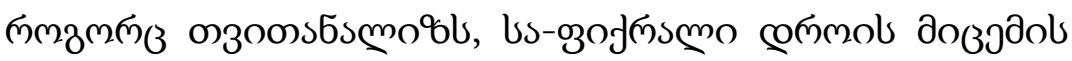

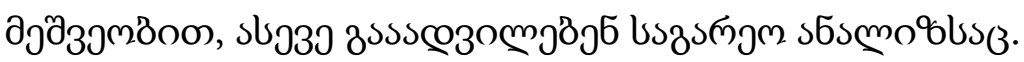

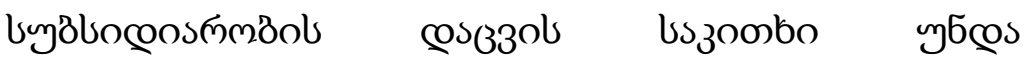

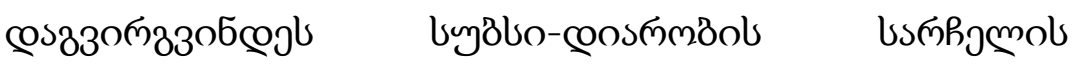

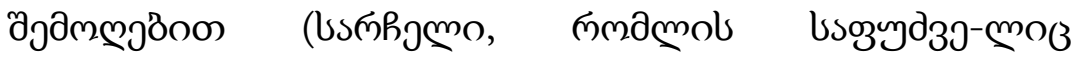

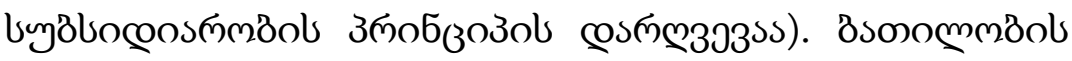

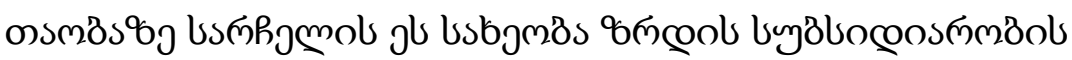

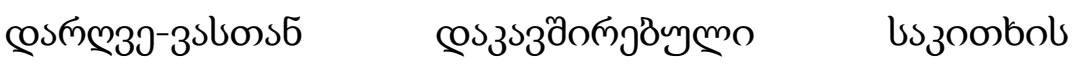

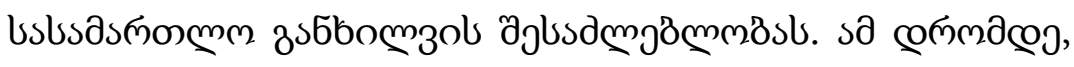

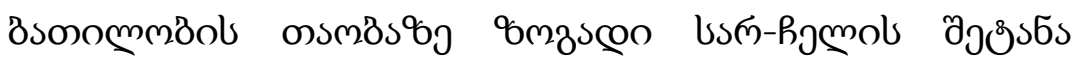

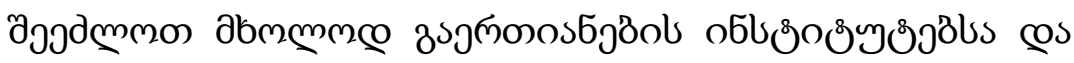

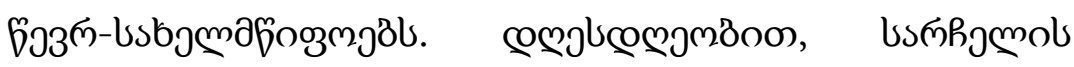

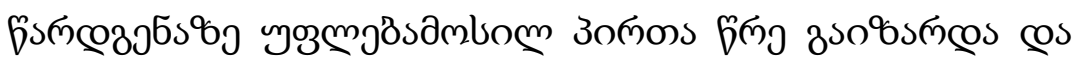

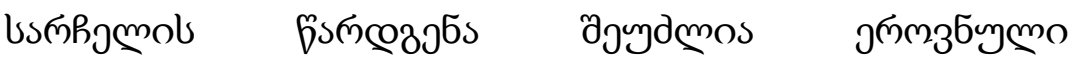


Зsলms

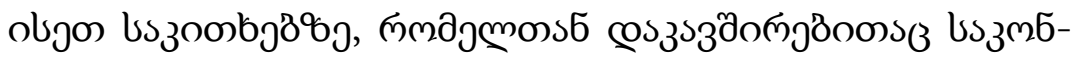

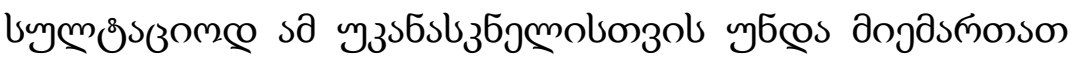

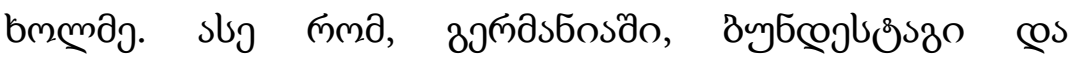

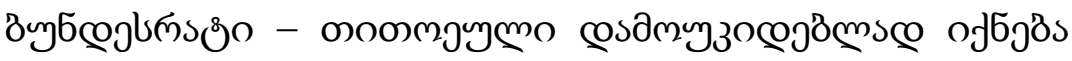

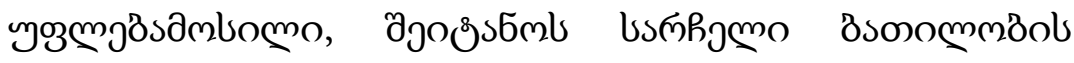

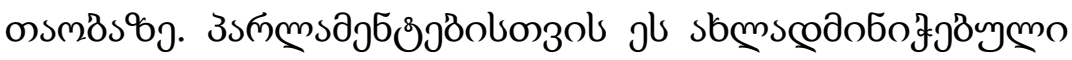

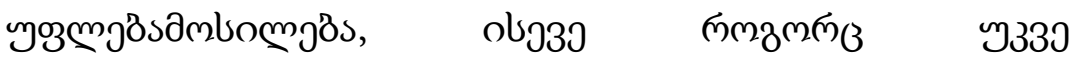

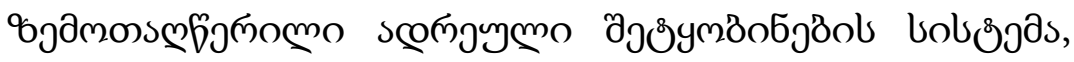

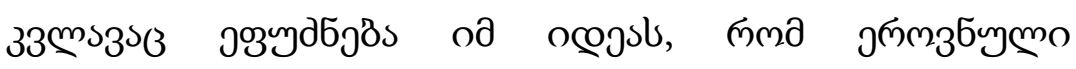

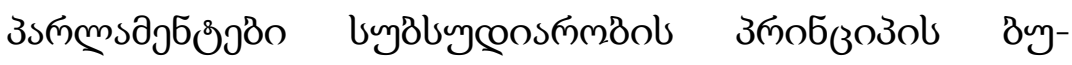

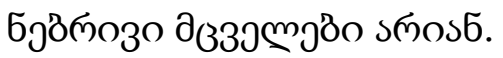

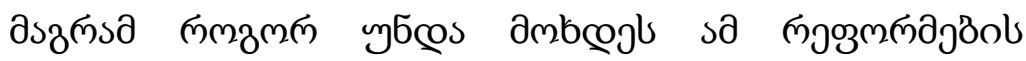

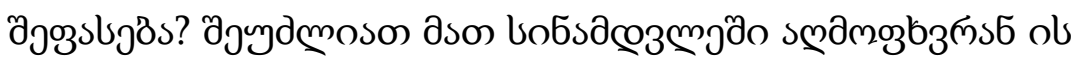

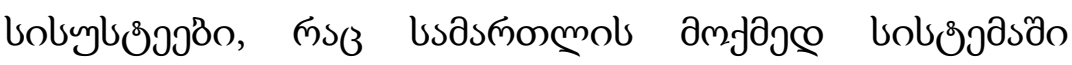

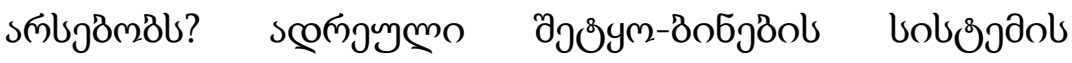

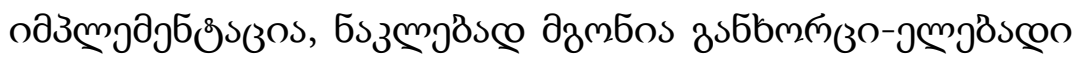

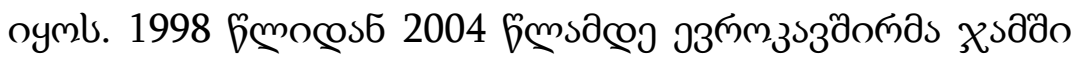

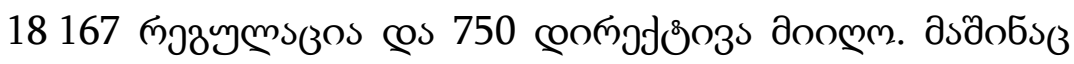

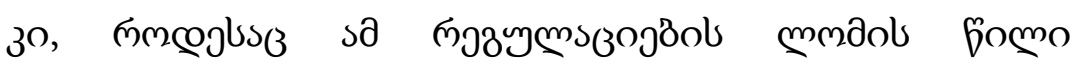

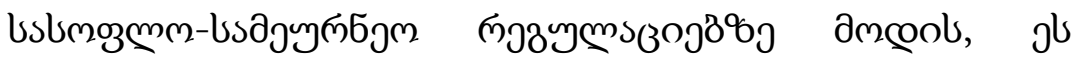

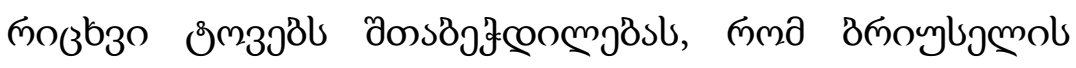

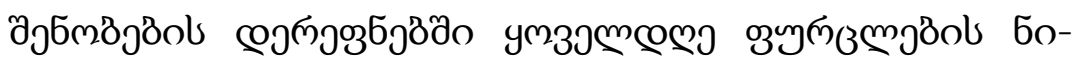

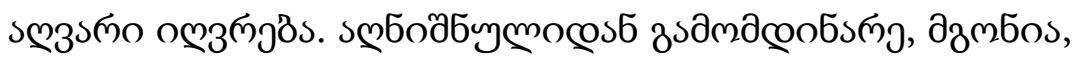

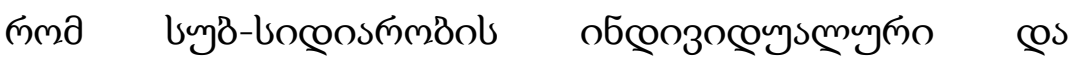

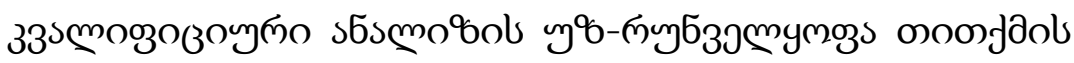




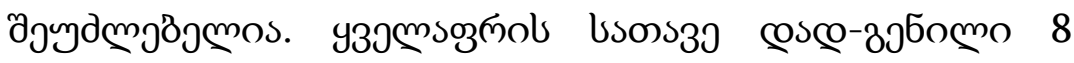

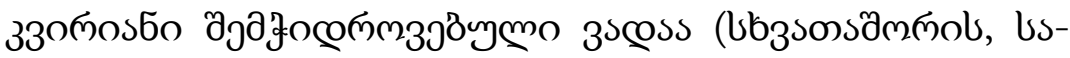

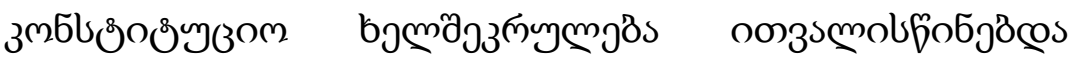

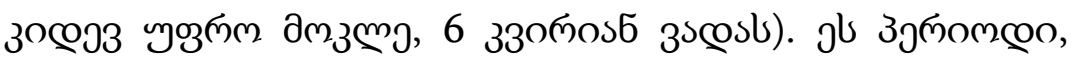

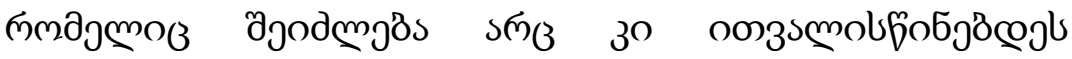

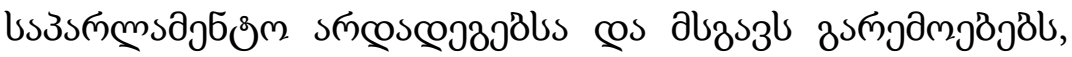

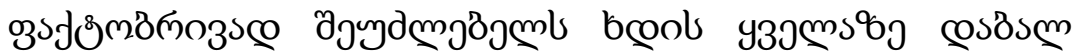

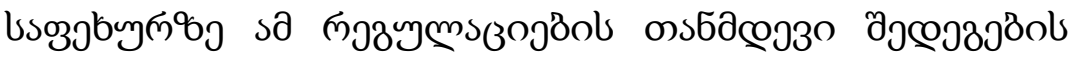

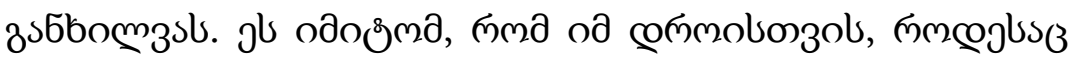

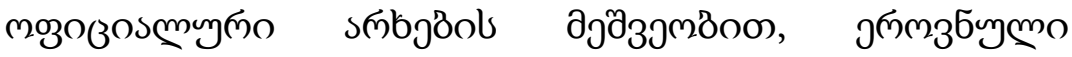

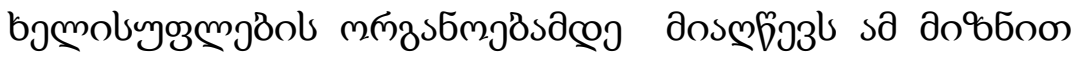

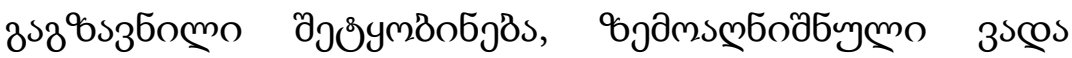
conco bбob zusuymo ofбjas.

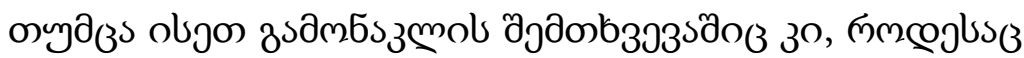

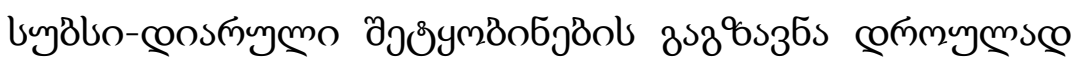

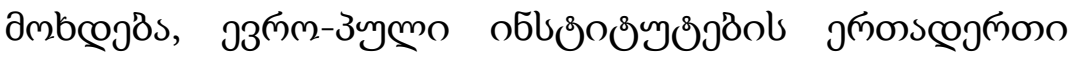

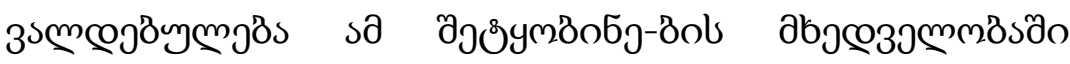

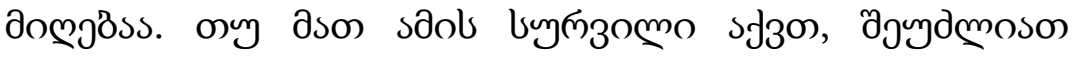

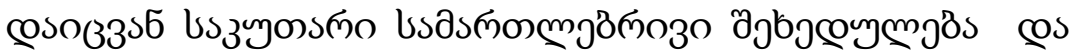

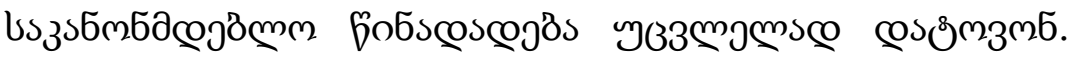

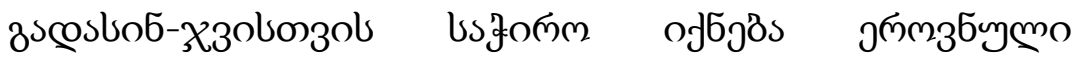

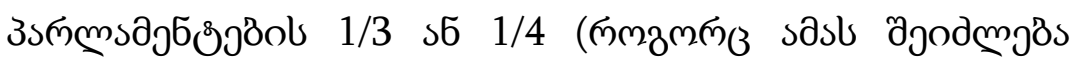

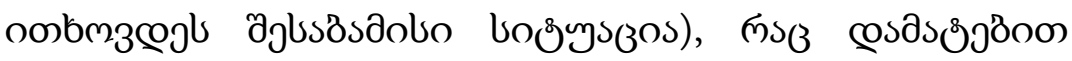

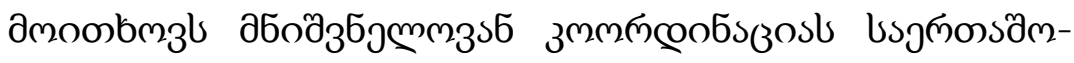

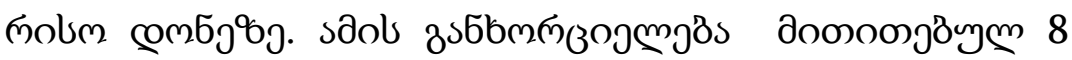

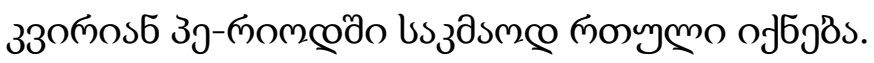




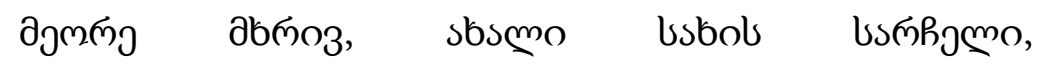

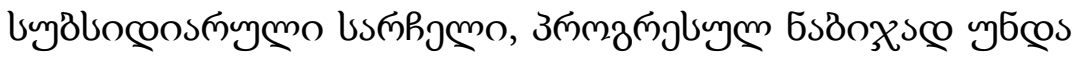

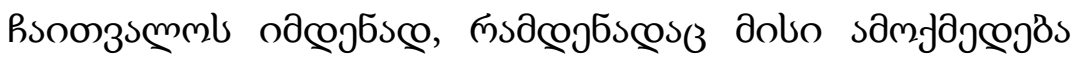

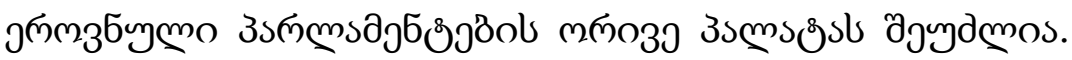

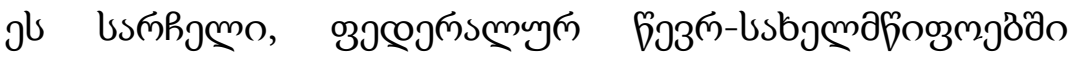

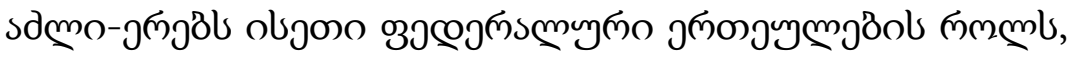

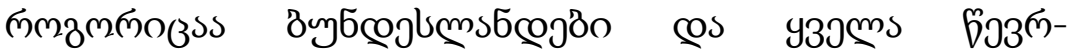

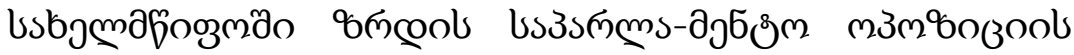

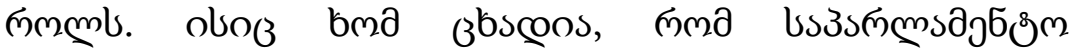

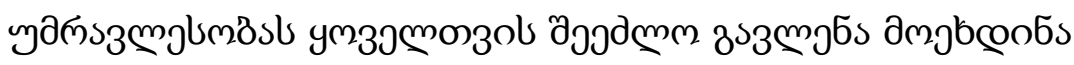

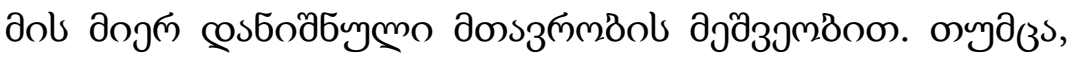

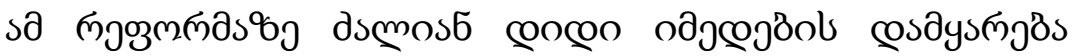

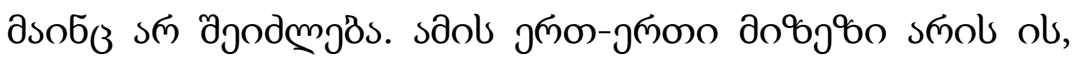

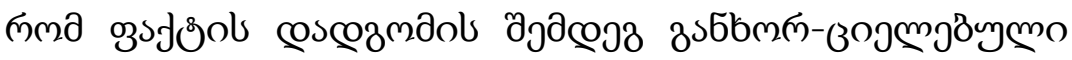

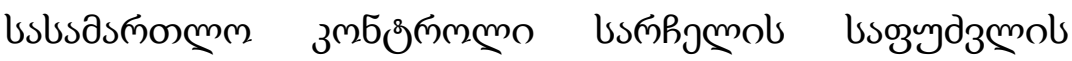

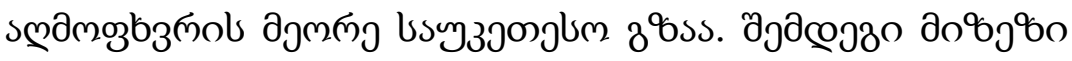

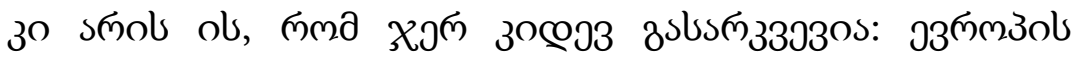

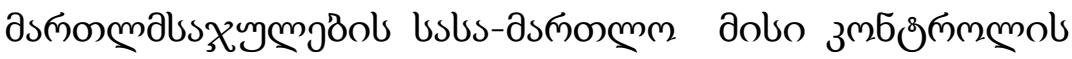
аs

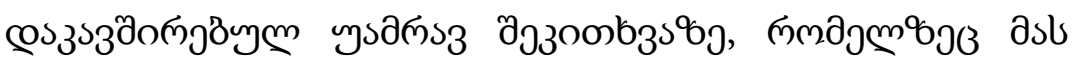

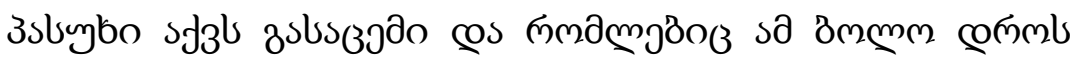

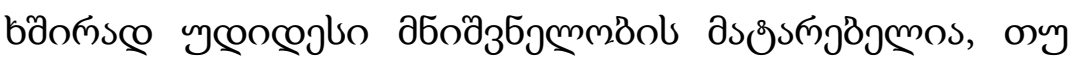
usbsasmonmm

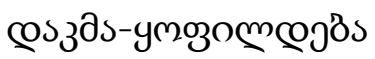

abmलnm@

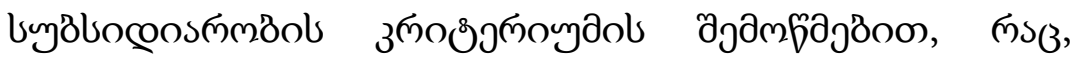

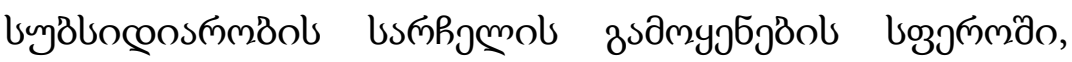

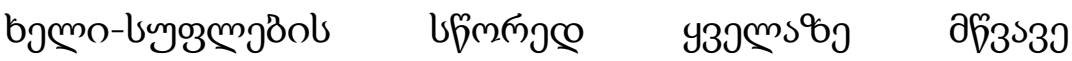




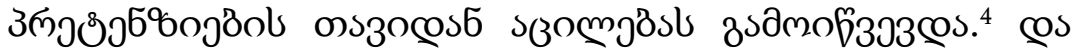

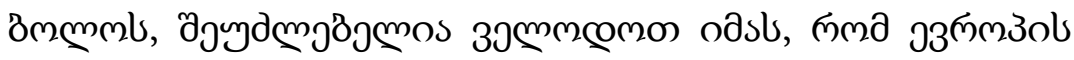

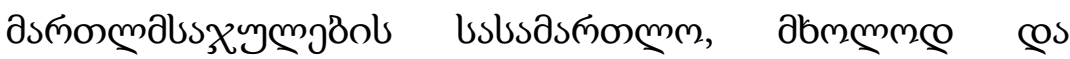

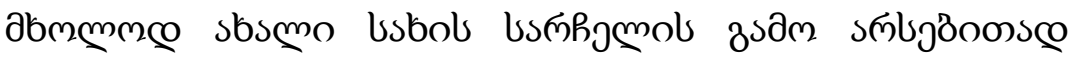

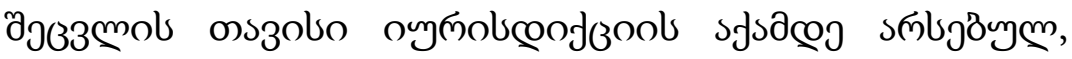

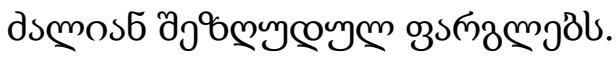

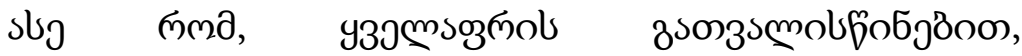

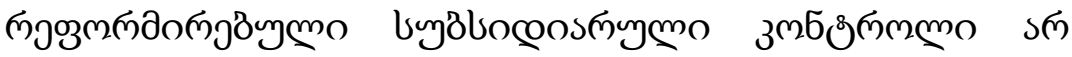

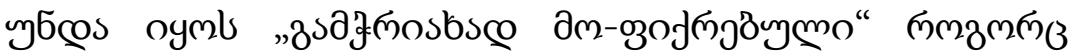

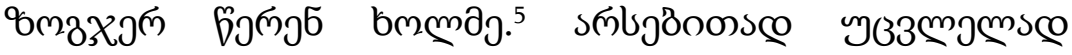

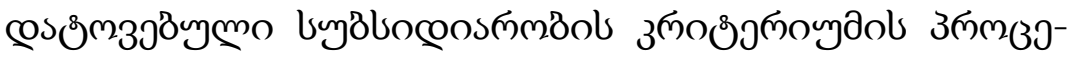

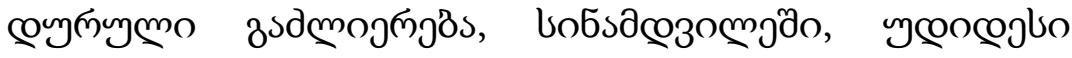

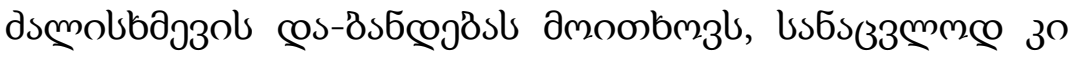

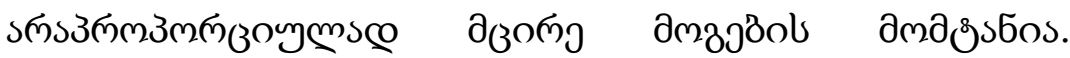

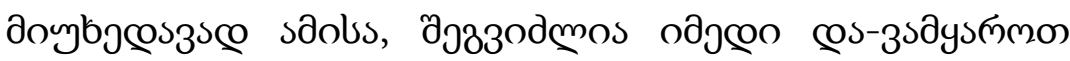

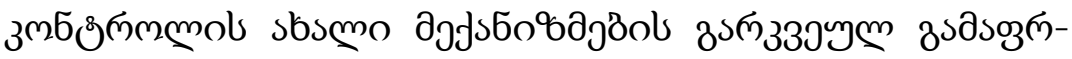

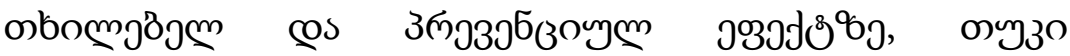

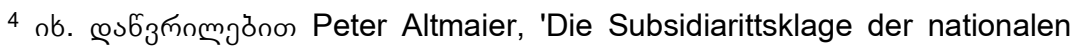
Parlamente nach dem Subsidiarititsprotokoll zum EU-Verfassungsvertrag', in Hans-Jorg Derra (ed.), Freihei, Sicherheitund Recht: PestschriftfirJfirgenM eyerpz/m 70. Geburtstag (Baden-Baden, Nomos 2006), p. 301 (318 f.);

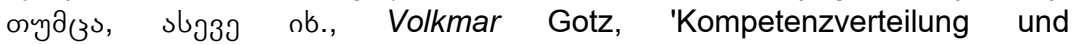
Kompetenzkontrolle in der Europischen Union', in Jurgen Schwarze (ed.), Der Vfassungsentwaqf des Europaischen Konvents (Baden-Baden, Nomos 2004), p. 43 (60 f.).

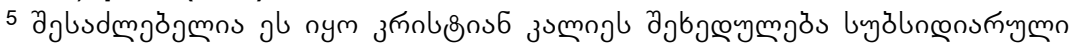

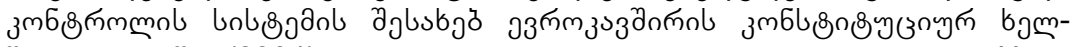

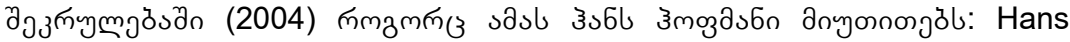
Hofmann, 'Europische Subsidiarititskontrolle in Bundestag und Bundesrat Das 8. Berliner Forum der Deutschen Gesellschaft fur Gesetzgebung (DGG)', ZG (2005), p. 66 (70). 


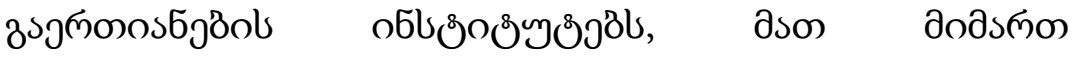

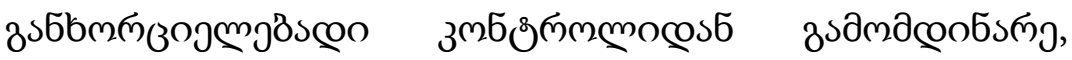

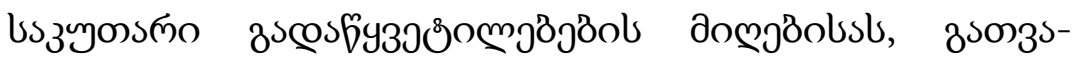

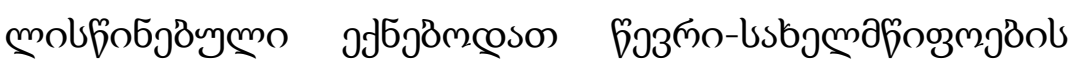
bogुmonbomy.

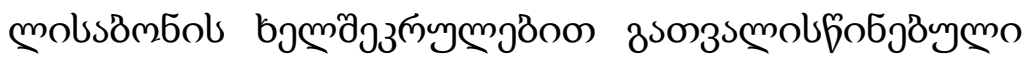

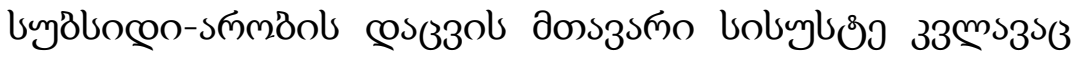

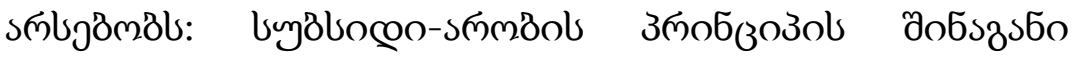

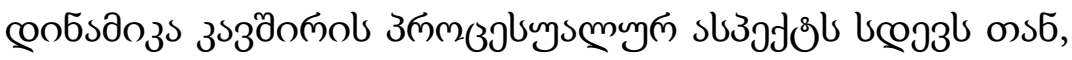

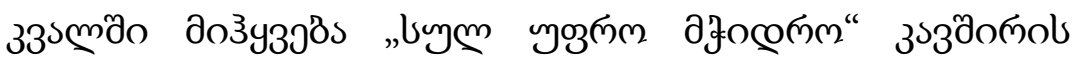

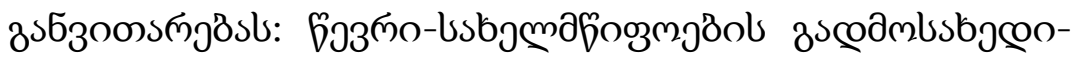

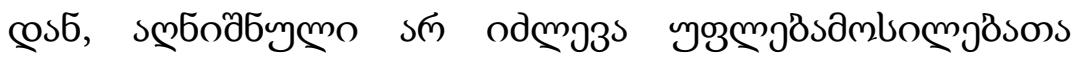

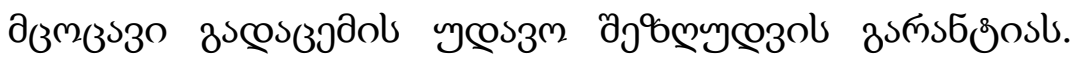

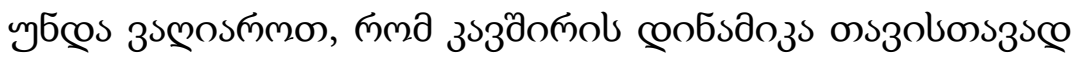

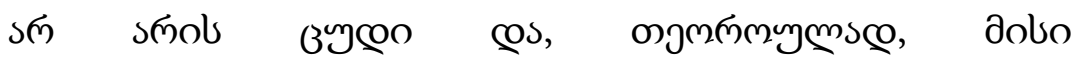

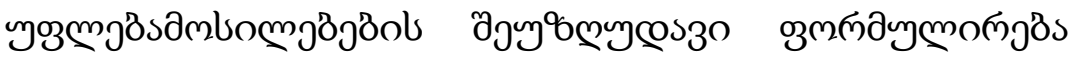

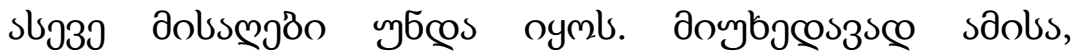

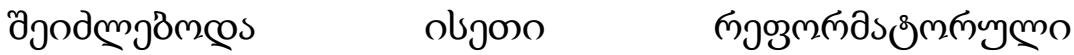

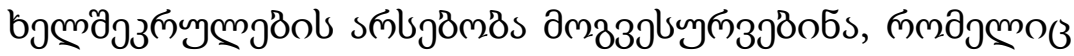

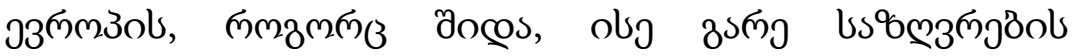

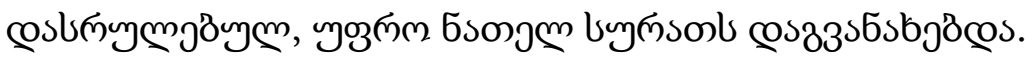




\section{EUROPE'S NEW REALISM: THE TREATY OF LISBON}

\section{Hans Jürgen Papier}

\section{Translated by Gvantsa Gugeshashvili*}

Abstract: The article by Hans Jürgen Papier discusses the institutional reforms of the Treaty of Lisbon. The author assesses whether the innovations of the Treaty are suited for restoring Union's capacity to act.

The author welcomes the changes in the organizational structure of the EU. He considers that the most far-reaching change results from the new architecture of the European Union as one of a unitary legal personality with a supranational character.

From the author's point of view, the reinforcement of the subsidiarity principle is the most valuable reform in the Treaty of Lisbon. However, the weakness of its protection is still here.

The author wishes the Treaty to give a clearer picture of Europe, of both its inner and outer boundaries.

Key words: EU, Treaty of Lisbon, New Europe, Supranational Character.

* Associate Professor, Academic Director of Michel Mouskhely Institute of Sulkhan-Saba Orbeliani University. orcid.org/0000-0003-4586-2731 


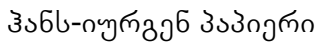

